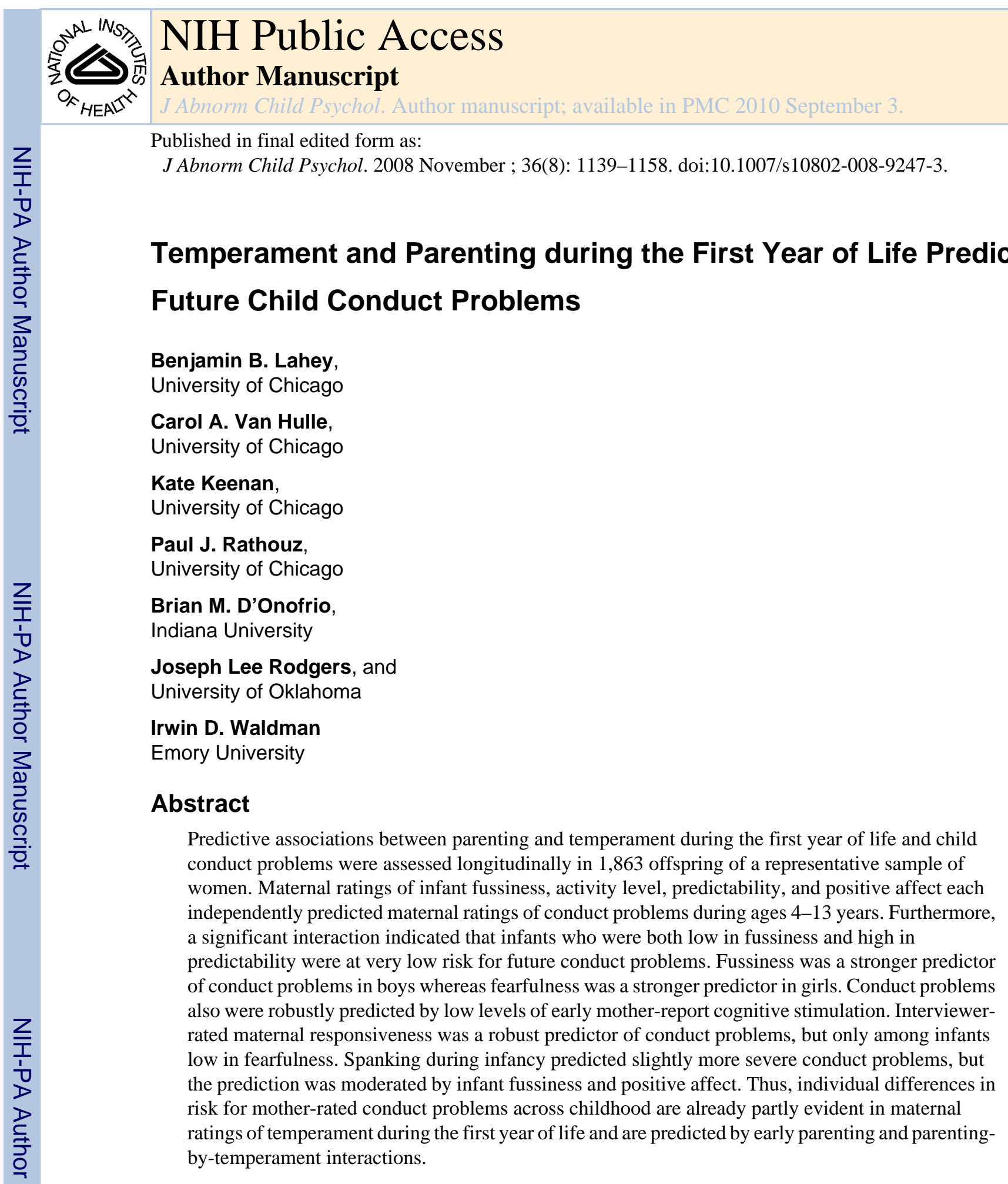

Many theorists have suggested that mothers who responsively meet the needs of their infants following birth provide a necessary foundation for the development of regulated and competent emotional and social behavior (Bornstein, 2002; Bowlby, 1958; Kochanska, 1997a). The infant plays an important role in this potentially critical process, as responsive parenting involves reciprocal transactions between infants and mothers (Anderson, Lytton, \& Romney, 1986; Bates et al., 1998; Bell, 1977; Chess \& Thomas, 1984; Lytton, 1990; Maccoby, 1992). Thus,

Submitting author: Benjamin B. Lahey, Ph.D., Department of Health Studies (MC 2007), University of Chicago, 5841 South Maryland Avenue, Chicago, IL 60637, Telephone: 773-702-2582, Fax: 773-702-1979, blahey @ uchicago.edu. 
it is likely that individual differences in maternal responsiveness reflect characteristics of the mother, dimensions of infant temperament, and interactions among these variables (Lerner, Nitz, Talwar, \& Lerner, 1989; Thomas \& Chess, 1977).

The "truly early starter model (TESM) of antisocial behavior" was advanced to apply a transactional view of early temperament and parenting to the origins of conduct problems (Shaw, Bell, \& Gilliom, 2000). The TESM includes the hypothesis that the combination of infant fussiness and lack of maternal responsiveness creates aversive mother-infant interactions which set the stage for coercive interactions that foster conduct problems later in childhood (Patterson, 1982). In addition, the TESM hypothesizes significant interactions (in the sense of greater than additive combinations) between infant temperament and early parenting. The specific hypothesis offered is the combination of low maternal responsiveness and aversive infant behavior (e.g., fussy and persistent bids for maternal attention) is associated with particularly high risk for later conduct problems. The TESM also suggests that the predictive associations between infant factors and later conduct problems may be stronger in boys than girls (Shaw et al., 2000).

Based on extensive non-human animal research, Meaney and Szyf (2005) offered a very different model of effects of parenting during infancy. They hypothesized that variations in maternal care during infancy have lasting effects of the offspring's behavior through "environmental programming." That is, variations in early parenting can cause enduring alterations in gene expression that can be passed on to future generations. Regardless of the specific theoretical model, there is considerable reason to suspect that experiences during infancy play an important and perhaps critical role in the origins of psychopathology. Understanding that role will require an understanding of which dimensions of infant temperament and early parenting operate independently or interactively to create vulnerability for later psychopathology.

\section{Infant Temperament}

Early temperament is viewed both as the earliest indicator of biologically-based individual differences that directly presage later psychopathology and as early childhood characteristics that influence, and interact with, the social environment to foster the learning of psychopathology (Bates, Pettit, Dodge, \& Ridge, 1998; Chess \& Thomas, 1984; Keenan, 2000; Sanson, Prior, Smart, \& Oberklaid, 1993; Shaw et al., 2000). Much remains to be learned about such hypothesized relations between infant temperament and later adjustment, however. As Caspi (2000) put it: "Behavioral differences among children are apparent very early in life... Are such behavioral differences, or temperamental styles, evanescent qualities or do they presage the life patterns to follow?" [p. 158]

A number of different models and measures of infant temperament have been advanced (Buss \& Plomin, 1975; Carey, 1970; Rothbart, 1981; Thomas \& Chess, 1977). Each distinguishes somewhat different dimensions of temperament, but they include individual differences in dimensions such as infant activity level, positive affect, fearfulness, fussiness, and predictable rhythmicity. Many previous longitudinal studies have examined the extent to which such dimensions of early temperament predict future conduct problems. Three reviews (Keenan, 2000; Sanson, Hemphill, \& Smart, 2004; Shaw et al., 2000) document that maternal ratings of temperament during the infant and toddler years significantly predict future maternal ratings of childhood conduct problems. Most previous studies used small and non-representative samples, but yielded generally consistent findings. Nonetheless, three basic questions remain largely unanswered: (1) how early in life does temperament predict future conduct problems, (2) which dimensions of temperament predict future conduct problems, and (3) over how long a period of future development does early temperament predict future conduct problems? Existing studies clearly suggest that temperament measured after the first year of life predicts 
behavior problems into middle childhood, but there is less evidence that temperament measured during the first year of life predicts future conduct problems beyond the preschool years. For example, Prior, Smart, Sanson, and Oberklaid (2001) found that ratings of infant temperament at 4-8 months predicted mother rated behavior problems at 3-4 years, but these early temperament ratings did not continue to predict behavior problems after the children reached 5 years. In contrast, Bates et al. (1998) found that temperamental resistance to control measured after the first year of infancy (at 13 and 24 months) did predict behavior problems into middle childhood. Similarly, Guerin, Gottfried, and Thomas (1997) found that maternal ratings of difficult temperament at 18 months predicted parent-rated conduct problems through age 12 years of age. In addition, two prospective longitudinal studies indicate that individual differences in temperament-like behavioral characteristics at age 3 years predict aggression in late childhood (Raine, Reynolds, Venables, Mednick, \& Farrington (1998) and predict antisocial behavior in early adulthood (Caspi, Moffitt, Newman, \& Silva, 1996).

Only four previous studies provide evidence relevant to the long-term prediction of later conduct problems from measures of temperament during the potentially important first year of life. A longitudinal study of approximately 120 infants found that maternal ratings of difficult temperament at 6 months predicted mother-rated conduct problems through age 17 years, but not teacher or youth reports of conduct problems (Olson, Bates, Sandy, \& Lanthier, 2000). A longitudinal study of 100 Finnish infants found that maternal ratings of fussiness at 6 months significantly predicted both parent and youth composite reports of a broad range of emotional and behavior problems at ages 14-15 years, but infant activity, fearful response to novelty, and biological predictability did not (Teerikangas, Aronen, Martin, \& Huttunen, 1998). In contrast, in a prospective study of 180 infants, maternal ratings of infant temperament at 3 and 6 months did not significantly predict maternal ratings of conduct problems during adolescence (Aguilar, Sroufe, Egeland, \& Carlson, 2000). In a sample of about 400 infants, Colder et al. (1998) found that infant fearfulness and activity level during the first year of life predicted conduct problems during 4-8 years in interaction (not individually), but did not test other dimensions of temperament as predictors. It is very important to continue to test the hypothesis that variations in temperament during the first year of life presage behavior problems into later childhood and beyond using samples with sufficient power to detect meaningful associations and interactions. Because some models of temperament suggest that interactions among dimensions of temperament may be important in predicting future problem behavior (e.g., Rothbart \& Bates, 1998), it will be important to continue to test such interactions.

\section{Role of Parenting During Infancy}

Because of the theoretical importance of parenting during infancy, a number of studies have prospectively linked measures of parenting during infancy to later conduct problems. Pettit and Bates (1989) conducted three observational assessments of 29 infant-parent dyads at three different ages and found that a pattern of parenting defined by affectionate contact ( 6 months), affectionate teaching (13 months), and verbal stimulation (24 months) inversely predicted behavior problems at 4 years. In a study of 125 low-income children, Shaw, Winslow, Owens, Vondra, Cohn, and Bell (1998) found that high maternal responsiveness at 12 months was inversely related to problem behavior at 42 months. Similarly, maternal report of spanking across $0-23$ months was found to predict conduct problems 4 years later, even after controlling for maternal report of difficult temperament during infancy and toddlerhood (Slade \& Wissow, 2004). Only two prospective studies have found links between parenting during the first year of life and conduct problems beyond the preschool period. In sample of 77 mostly substanceabusing women, observational ratings of maternal behavior at 4 and 12 months were found to predict child conduct problems at 10 years of age (Wakschlag \& Hans, 1999). In addition, in a sample of about 120 mothers, observations of warm maternal responsiveness when the infant was age 6 months of age predicted both mother-rated and youth reported conduct problems at 
age 17 years (Olson et al., 2000).. In addition, low levels of cognitive stimulation and affection at 13 months predicted youth reported conduct problems at age 17 years in this study (Olson et al., 2000). In contrast, a study of 180 infants did not find that observed maternal responsiveness at 6 months and other early parenting dimensions predict maternal ratings of conduct problems during adolescence (Aguilar et al., 2000).

There is some evidence from studies of preschool and school age children of interactions among parenting variables on child outcomes. Specifically, the degree of association of spanking with child conduct problems is different at different levels of maternal emotional support (McLoyd, \& Smith, 2002). Therefore, it is important to explore potential interactions among parenting behaviors in samples with sufficient power to detect interactions.

\section{Demographic Factors in Temperament and Parenting During Infancy}

The development of conduct problems must be understood in the context of its complicated demography (Loeber, Farrington, Stouthamer-Loeber, \& Van Kammen, 1998). Much can be learned about these demographic differences in conduct problems by studying temperament and parenting in infancy. For example, there is clear evidence that males exhibit more conduct problems than females after age 4 years (Keenan \& Shaw, 1997; Lahey, Miller, Gordon, \& Riley, 1999; Moffitt, Caspi, Rutter, \& Silva, 2001). It is interesting, then, that literature reviews have not found evidence of sex differences in temperament or parenting during infancy (Keenan \& Shaw, 1997, 2003). Subsequent studies have generally replicated these conclusions, although Gartstein and Rothbart (2003) found that 3-12 month infant girls were rated as significantly less active and more fearful than male infants. Similarly, a study of a large Finnish sample found that infant girls were rated significantly higher on both temperamental fearfulness and predictability (Martin, Wisenbaker, \& Huttunen, 1997). This conflicting evidence makes it important to test for sex differences in infant temperament in representative samples that are large enough to detect such differences. It also would be important to know if there are sex differences in the magnitudes of predictive associations between temperament and parenting and later conduct problems. If there are neither sex differences in levels of infant temperament and parenting, nor in the extent to which they predict later conduct problems, that would suggest that the later emergence of sex differences in conduct problems is due to factors that come into play after infancy. On the other hand, if there are sex differences in infant temperament or parenting, or in the magnitudes of predictions of later child conduct problems, that would imply that infant variables play a role in the origins of sex differences in later conduct problems.

There also is evidence that children living in lower socioeconomic environments are more likely to develop conduct problems than children living in higher socioeconomic environments (Lahey et al., 1999). Correspondingly, there is evidence that some aspects of the parenting of infants, such as cognitive stimulation, vary with socioeconomic status (Bornstein, Hahn, Suwalsky, \& Haynes, 2003; Karrass, VanDeventer, \& Braungart-Rieker, 2003). If socioeconomic differences in the aspects of early parenting that predict future conduct problems can be identified consistently in representative samples, that would suggest that early parenting could be a factor that contributes to socioeconomic differences in conduct problems (Bornstein et al., 2003). There is currently little evidence on race-ethnic differences in parenting during the first year of life from representative samples, but one study found that African American mothers report using spanking during preschool and elementary school years more often than Hispanic and Non-Hispanic European American mothers (McLoyd, \& Smith, 2002). In addition, some studies have found that spanking predicts higher levels of childhood conduct problems in Non-Hispanic European American families but not in African American families (Deater-Deckard \& Dodge, 1997; Slade \& Wissow, 2004). Again, describing any raceethnic differences in levels of parenting and temperament in infancy, and any differences in 
their predictive relations to later conduct problems, will inform theories of the origins of conduct problems in important ways.

\section{Goals and Hypotheses}

The goals of the present paper are to determine if temperament and parenting during the first year of life, both singly and in interaction with one another, predict future conduct problems across 4-13 years of age. Tests will be conducted using prospective longitudinal data on the same children from infancy through early adolescence in a large and diverse population-based sample. Based on theory and previous studies, a number of specific hypotheses will be tested:

1. Dimensions of infant temperament that may reflect what is referred to generally as "difficult temperament" (i.e., high activity, high fearfulness, and low predictability) are hypothesized to predict future child conduct problems (Guerin et al., 1997; Olson et al., 2000). In particular, infant fussiness is predicted to be robustly related to future child conduct problems (Teerikangas et al., 1998; Shaw et al., 2000).

2. Maternal responsiveness during the first year of life is predicted to be inversely related to future child conduct problems (Kochanska, 1997a; Olson et al., 2000; Shaw et al., 2000; Wakschlag \& Hans, 1999). In addition, cognitive stimulation will be inversely related to future child conduct problems (Olson et al., 2000).

3. A significant interaction will be found between maternal responsiveness and dimensions of infant temperament that the mother may find to be aversive (infant fussiness, fearfulness, and activity) in the prediction of future child conduct problems (Shaw et al., 2000).

4. Associations between infant fussiness and later conduct problems, and between maternal responsiveness and later conduct problems, will be stronger in boys than girls (Shaw et al., 2000).

5. Spanking will predict childhood conduct problems more strongly in Non-Hispanic European American families than African American families (Deater-Deckard \& Dodge, 1997; Slade \& Wissow, 2004).

In addition, because we have only begun to study relations between factors in the first year of life and later conduct problems, all main effects and all possible interactions among temperament dimensions, among parenting dimensions, and between temperament and parenting dimensions will be tested in an exploratory spirit. The statistical power provided by this large sample provides an unprecedented opportunity to test interactions. These systematic tests of all main effects and interactions will provide an empirical basis for future refinements of theoretical models of early factors in the origins of conduct problems. Demographic variables related to childhood conduct problems will be included in these analyses to describe any demographic differences in temperament and parenting, to control potential demographic confounds, and to test interactions between demographic factors and infant predictors.

\section{METHOD}

\section{Sample}

\section{Mother-Generation Sample: The National Longitudinal Survey of Youth}

(NLSY79)-The NLSY79 survey was funded by the Bureau of Labor Statistics to study the future U.S. workforce. A nationally-representative household sample of 6,111 14-22 year old male and female youth who were not in the military was selected for the NLSY79 using a complex survey design. An additional sample of 3,652 African American and Hispanic youth was selected for the NLSY79 mother-generation sample to oversample these groups. The NLSY79 sample available for the present analyses consisted of the 4,926 females $(1,472$ 
African American, 977 Hispanic, and 2,477 non-Hispanic European American and other groups) who had given birth to children who have participated in the assessments of offspring. The present analyses are based on data from the 1986-2004 assessments of the offspring. The response rate for the initial NLSY79 assessment was $90 \%$ of the eligible sample. Participants were re-interviewed annually from 1979 through 1994 and every two years since then.

Retention rates for the NLSY79 during follow-up assessments were $90 \%$ or better during the first 16 waves and have stayed above $80 \%$ since.

\section{Offspring-Generation Sample: Children of the NLSY79 (CNLSY)-Biennial}

assessments of the biological children of women in the NLSY79 began in 1986, with 95\% of the offspring assessed (Chase-Lansdale, Mott, Brooks-Gunn, \& Phillips, 1991). For budgetary reasons, however, a random 38\% of the African American and Hispanic oversamples was not recruited in 2000. The data missing from the 2000 assessment can be considered to be missing completely at random (Little \& Rubin, 1987). The average retention rate for the repeated assessments was above $90 \%$ through 2004 . Although there were relatively little missing data due to nonparticipation, however, a large amount of data was missing by design. Only a subset of the full sample of CNLSY sample could be used in the present analyses because of the ages at which they were assessed. The offspring whose data could be used in the present analyses participated in an assessment of temperament and parenting at 0-11 months of age. Nearly equal numbers of infants of each age in months participated, with $46.4 \%$ being less than 6 months in age ( $\mathrm{M}=5.8$ months, $\mathrm{SD}=3.5$ months). In addition, the subset of the CNLSY sample was limited to participants whose childhood conduct problems had been rated by their mothers in at least 2 of the 5 biannual assessments across $4-13$ years. Because different offspring entered the study in different calendar years following their births, different offspring could be assessed different numbers of times through the last assessment in 2004 for which data are available. The percent of participants with completed assessments of conduct problems at each age was: $4-5$ years $=93 \% ; 6-7$ years $=92 \% ; 8-9$ years $=82 \% ; 10-11$ years $=70 \%$; and $12-13$ years $=$ $61 \%$. Even at ages $12-13$ years there were 1,131 assessments, providing substantial power to test predictive associations. Among the participants in the present analyses, $86 \%$ had 3 or more assessments of their childhood conduct problems, and $70 \%$ had 4 or more assessments.

Because children could enter the biennial sequence of assessments only in even numbered calendar years, only half of the offspring of the NLSY79 mothers were eligible for the assessment of infant temperament during the first year of life, with the remaining half not included in the present analyses. Other CNLSY offspring were not included in the present analyses because they were too old for the temperament assessment at the time of the first assessment in 1986 or have not yet been assessed twice during childhood. These missing data can be considered missing at random contingent (Little \& Rubin, 1987), which is

accommodated well by the longitudinal analyses. Nonetheless, the data missing by design are likely to influence its representativeness. Therefore, it is necessary to test for potential biases in the subsample used in the present analyses.

It should be noted that five papers cited in this paper also were based on varying subsets of observations from the CNLSY. Colder et al. (1998) predicted child outcomes at 8 years using data from the 1986-1994 assessments on a restricted subsample and Slade and Wissow (2004) used data from the 1986-1998 assessments. McLoyd and Smith (2002) assessed the association of parenting measures with change in a global measure of child adjustment across 1988-1994 by following CNLSY children who were 4-5 years of age in 1988. In addition, two papers on the validity of the Home Observation for Measurement of the Environment (HOME-SF; Bradley, Corwyn, Pipes McAdoo, \& García Coll, 2001; Bradley, Corwyn, Burchinal, Pipes McAdoo, \& García Coll, 2001) conducted time-varying correlational analyses using data from the 1986-1994 assessments. 
The present analyses differ from these earlier CNLSY papers in three main ways. First, the present analyses are based on at least three additional biannual assessments of the CNLSY sample that were not included in the earlier papers (i.e., 2000i.e., 2002, and 2004). This both allows coverage of a longer span of development and allows the analyses to be based on the offspring of NLSY79 mothers who were born over a broader range of maternal ages than in previous papers. The latter means than the data used in the present analyses are less biased by early maternal age and more representative of the U.S. population. Second, unlike most previous papers, we limited our analyses to the predictor variables of temperament and parenting measured during the first year of life and limited our response variable to conduct problems, rather than the broader and less specific measures of child maladjustment (which conflated internalizing and externalizing problems) used in most previous studies of this sample. Third, the present analyses tested predictive associations of early parenting with future conduct problems while controlling for early temperament and vice-versa.

Participants Available for Preliminary Factor Analyses-Maternal ratings of infant temperament obtained at 0-11 months were available on 2,562 offspring of the CNLSY mothers. Respondents other than the child's biological mother completed temperament ratings in $<1 \%$ of cases. Eighteen $(0.7 \%)$ children were dropped because they had missing data on > $50 \%$ of temperament items. After dropping these children, $94 \%$ of the 2,544 children had missing data on no items and $98 \%$ had missing data on $<2$ items.

Participants Available for Longitudinal Analyses-Infant temperament ratings obtained at 0-11 months were available on 2,040 children who also had at least two follow up assessments of child conduct problems over 4-13 years. Because 177 parents did not provide information on family income, which was an essential covariate in all longitudinal analyses, the analyses were based on the remaining 1,863 participants. Among these participants, there were $\leq 0.5 \%$ missing data on each infant temperament variable. There were fewer completed mother-infant interactions during which interviewers rated parenting behaviors $(n=1,519)$, however, because infants were not always available at the time of the assessment of the mother. Within the group with completed mother-infant interactions, there was $<0.5 \%$ missing data on each parenting measure. The characteristics of the participants in the present analyses are described in Table 1. Correlations among the demographic and infant predictor variables are presented in Table 2.

\section{Measures}

Federal health and policy studies, such as the CNLSY, use a measurement strategy that is designed to assess multiple constructs without overburdening participants. Short forms of scales often are developed that maximize correlations with full scales. Therefore, repeated assessments of large sample sizes are used to detect reliable signals in the data.

Measures of Infant Temperament-Mothers rated their 0-11 month old infants on 17 temperament items using a 5-point scale: almost never; less than half the time; half the time; more than half the time; almost always. These temperament items were based primarily on a subset of the items used in the Infant Behavior Questionnaire (IBQ; Rothbart, 1981) that were selected to represent five dimensions of infant temperament: activity levels, predictability of cycles and moods, positive affect, fearfulness, and fussiness (Mott, Baker, Ball, Keck, \& Lenhart, 1995).

There is disagreement regarding the factor structure of these CNLSY temperament items. Based on an exploratory factor analysis of a subset of the across 6-23 months, Baydar (1995) recommended distinguishing only 2 temperament dimensions. In contrast, the NLSY User's Guide recommends distinguishing 5 factors, but also provides alternative scorings for 
fewer factors. In order to choose among these recommendations, we conducted confirmatory factor analyses (CFAs) using Mplus 4.1 based on item ratings residualized on the infant's age in months at the time that temperament was rated, while taking clustering within CNLSY families into account. The 5-factor temperament model was based on the scale structure originally assumed for the CNLSY infant temperament measure. The fit of this model was compared to nested models in which scales were combined to create broader scales, as suggested by Mott et al. (1995) and consistent with other models of temperament (e.g., Bates, 1992). In the 4-factor model, fearfulness and fussiness were combined to define negative affectivity. In the 3-factor model, fearfulness, and fussiness, and the inverse of positive affect were combined to define emotionality. In the 2-factor model predictability, fearfulness, fussiness, and the inverse of positive affect were combined to define difficult temperament. All temperament dimensions were combined in the 1 -factor model.

The recommended 5-factor model of CNLSY temperament items fit significantly better than the next best-fitting 4-factor model (Satorra-Bentler scaled-difference $\chi^{2}=280.13, d f=4, p$ $<.0001)$. All other models fit significantly less well. Fit indices for the 5-factor model indicated a close fit (comparative fit index $=.94$; root mean square error of approximation $=.04$ ).

Therefore, the five infant temperament scales used in the present analyses were: activity level (squirms and kicks during feeding; waves arms during feeding; moves around in the crib during sleep), predictability (sleepy about the same time each evening; hungry about the same time each evening; wakes up in the same mood each morning), fearfulness (cries or turns away from strangers; cries or turns away from unfamiliar dog or cat; cries when left alone in a room; cries or turns away from a doctor, dentist, or nurse); positive affect (smiles or laughs when you play with him or her; smiles or laughs when plays alone; smiles or laughs in the bath), and fussiness (often fussy or irritable; trouble soothing infant when crying or upset; often cries or fusses compared to most babies; cries or becomes upset in response to noise). The item with the lowest loading on any factor was crying in response to noises. We tested an alternative model in which this item loaded on the fearfulness factor with other crying items, but the loading was still <.30 and the fit of the alternative model was not better than the original 5factor model. On the assumption that crying in response to noises is more related to sensory modulation than fearfulness (Dunn, 2002; Goldsmith et al., 2006), we dropped this item. Cronbach's alpha coefficients for the raw temperament scales were modest: activity $=.66$; predictability $=.59$; positive affectivity $=.71$; fearfulness $=.61$; and fussiness $=.60$.

Measure of Parenting During Infancy-Parenting at 0-11 months was measured using the CNLSY Infant/Toddler Short Form of the widely-used HOME-SF (Caldwell \& Bradley, 1984). The HOME was constructed rationally and through factor analysis (Bradley \& Caldwell, 1984) and has been validated by correlations with observational measures of parenting (Bradley, Caldwell, \& Corwyn, 2003). The Infant/Toddler HOME-SF is composed of 8 ratings of the mother's parenting and the physical home environment made by the interviewer following the assessment of the mother and infant, and 10 maternal-report items on her parenting behaviors and the home environment. Although there are mean differences in HOME-SF items across U.S. race-ethnic groups in the CNLSY, differences related to family socioeconomic status are greater and account for most race-ethnic differences when controlled. Moreover, differences in HOME-SF scores related to poverty are proportional across European American, African American, and Hispanic American groups (Bradley, Corwyn, Pipes McAdoo, \& García Coll, 2001).

Three dimensions of parenting are distinguished in the Infant/Toddler HOME-SF: maternal responsiveness, cognitive stimulation, and spanking/restraint. In a study of CNLSY data from the 1986-1994 assessments, Bradley, Corwyn, Burchinal, Pipes McAdoo, and García Coll (2001) treated the three HOME-SF dimensions as time-varying covariates across 4-13 years. They found that cognitive stimulation and maternal responsiveness were concurrently 
associated with the development of receptive vocabulary and cognitive stimulation and spanking/restraint were concurrently associated with the global total score on the mothercompleted Behavior Problem Index (Mott et al., 1995). Similarly, Linver, Brooks-Gunn, and Kohen (2002) found cognitive stimulation to be concurrently correlated with a global behavior problem score during the preschool years.

We conducted CFAs to test the three-dimensional structure of the HOME-SF parenting items, partly because we dropped four items from the HOME-SF to focus more on maternal parenting than on the home environment and perhaps to make the scale more applicable across socioeconomic levels and cultures: number of soft/role play toys child has; number of push/ pull toys child has; child sees father figure daily; child often eats with mother and father. The recommended 3-factor model of age-adjusted ratings of the Infant/Toddler HOME-SF parenting items fit significantly better than the next best-fitting 2-factor model (Satorra-Bentler scaled-difference $\left.\chi^{2}=1,222, d f=2, \mathrm{p}<.0001\right)$. Fit indices for the 3 -factor model indicated a close fit (comparative fit index $=.90$; root mean square error of approximation $=.04$ ). These three parenting dimensions were maternal responsiveness (interviewer rating of the mother speaking to child 2 or more times; mother responding verbally to child's speech; mother kissing, hugging, or caressing the child; mother providing interesting toys or activities; mother keeping child in view; and the play environment in the home being safe), cognitive stimulation (maternal reports that the child often gets out of house; child has a number of books; mother often reads to child; child is often taken to grocery store; mother often talks to child while working or doing chores), and spanking/restraint (mother report that she spanked the child at least once in the last week; interviewer report that the mother slapped or spanked child at least once during assessment; interviewer report that the mother physically restricted child at least 3 times during the observation).

Cronbach's alpha coefficients for the three parenting dimensions were modest: cognitive stimulation $=.58$; maternal responsiveness $=.68$; and spanking/restraint $=.28$. Because the internal consistency of spanking/restraint was unacceptable, we created a dichotomous indicator of spanking based on either the mother reporting spanking the infant during the last week or the interviewer observing spanking during the assessment. The prevalence of motherreported spanking was $7.3 \%$ and the prevalence of observed spanking was $1.7 \%$, with $8.1 \%$ of mothers being reported to spank by one or both reports. The two reports of spanking cooccurred at greater than chance levels (odds ratio $=5.30 ; 95 \%$ confidence interval $=2.2-12.4$ ), providing validation of each report of spanking.

Measure of Child Conduct Problems-Across 4-13 years of age, mother's rated their children's adjustment using the Behavior Problem Index (BPI; Peterson \& Zill, 1986). The BPI was created for the CNLSY by selecting the items from the Child Behavior Checklist (Achenbach, 1978) that had the strongest correlations with the corresponding CBCL factor scores (Peterson \& Zill, 1986). Mothers rated each of their children in each assessment wave using a 3-point scale for each item: "often true" $=2$, "sometimes true" $=1$, or "not true" $=0$. Based on similarities to items used in previous studies (Lahey et al., 2006), mean ratings of 7 BPI items were selected before data analysis to define child conduct problems: cheats or tells lies; has trouble getting along with teachers; disobedient at home; disobedient at school; bullies or is cruel or mean to others; breaks things on purpose or deliberately destroys his/her own or another's things; and does not seem to feel sorry after misbehaving. To test this selection of items, we conducted a confirmatory factor analysis of the 13 "externalizing" items in the BPI and found that the best-fitting model distinguished a factor comprised of these 7 conduct problem items from other items that measured hyperactive and oppositional behavior (D’Onofrio, Van Hulle, Waldman, Rodgers, Harden, Rathouz, \& Lahey, 2008). Across ages 4-13 years, the range of Cronbach's alpha coefficients for the conduct problems measure ranged across age from .68-.80, median $=.74$ (Lahey et al., 2006). Importantly, the CNLSY 
measure of child conduct problems is valid in the sense of robustly predicting convictions for nontrivial offenses during adolescence in the CNLSY (Lahey et al., 2006).

\section{Methods of Longitudinal Data Analysis}

Longitudinal tests of infant predictors of future childhood conduct problems over 4-13 years used longitudinal Poisson regression models estimated in generalized estimating equations (GEE; Zeger \& Liang, 1986), specifying autoregressive correlation structures in SAS GENMOD. These analyses were weighted using the mother's 1986 sampling weight to assign equal weights to siblings within families. GEE models the average value of the response variable for each subset of individuals who share the same value of the predictor variable. Because GEE is based on estimates of averages rather than the entire distribution of values, GEE is less restricted by distributional assumptions than other approaches to longitudinal analysis. All GEE models were conducted specifying Poisson working distributions, but other longitudinal models, GEE can be used when distributions of values of response variables do not conform exactly to a particular distribution (normal, Poisson, etc.).

All statistical tests in the present GEE analyses used robust ("empirical") standard errors because an adjustment for overdispersion from the Poisson distribution is automatically included and its use reduces concern about correct specification of the within-subject covariance structure. Like the other cited studies of the CNLSY sample, the clustering of the sample within sampling units and families was not formally modeled in these analyses. Fortunately, the robust standard errors used in GEE also minimize the effect of any incorrect specification of standard errors due to such clustering.

In all cases, predictive associations between infancy variables and later child conduct problems were tested in simultaneous longitudinal regression analyses in which each infant predictor of subsequent child conduct problems was tested while controlling for all other predictors and the demographic control variables (the child's age in years at the time of each assessment of child conduct problems, the infant's sex (coded $1=$ males; $0=$ females), maternal age at first birth, race-ethnicity, and total family income). In the log-linear models conducted in GEE, the regression coefficient $(\beta)$ represents the log relative mean count of conduct problems for a oneunit difference in the predictor variable. For example, in the model predicting conduct problems (range 0-11 problems) across 4-13 years from age-adjusted units of infant fussiness (range -3 through 9), adjusting for time, demographic variables, and the other dimensions of temperament, the coefficient of $\beta=0.05$ indicates each of the 12 single-unit differences in fussiness was independently associated with $5 \%$ greater conduct problems in each wave because $\exp (0.05)=1.05$. Interpreting $\beta$ as an estimate of "effect size" in this way in GEE, however, requires recognition that the range of scores for each predictor variable differs. As a result, a smaller $\beta$ for a predictor with a larger range of scores could indicate a stronger association than a larger $\beta$ for a predictor with a smaller range of scores. Therefore, more straightforward supplemental estimates of effect size also were provided for key findings.

After testing "main effects" for all predictors, all predictor-by-age (of the child at each assessment of conduct problems across 4-13 years) interactions were tested. A significant predictor-by-age interaction would indicate that magnitude of the prediction of child conduct problems changed over 4-13 years. No predictor-by-age interactions were significant, however.

Controlling the demographic covariates, we tested the interaction of each temperament measure (before residualizing for age in months) with the infant's age in months when temperament was measured to determine if these temperament measures predict future conduct problems differentially when temperament is measured at different ages during the first year of life. None of the interactions was significant at $p<.05$. 
An unadjusted alpha level of $p<.05$ was used based on the assumption that Type II errors are more serious than Type I errors during the early stages of research on a phenomenon (Cohen, 1982). That is, Type I errors are likely to be detected by future failures to replicate, whereas Type II errors may discourage future research (Cohen, 1994). If one were to apply a Bonferroni correction to the alpha level for the primary regression model (predicting childhood conduct problems using the five infant temperament scales, three dimensions of parenting during infancy, five demographic control variables, and testing the repeated assessment effect of age, the corrected alpha level would be $p<.0033$. As reported below, some infant predictors would remain statistically significant (i.e., infant fussiness and maternal cognitive stimulation) following such an adjustment, but others would not. Moreover, our emphasis is not on significance tests but on estimates of effect sizes for the predictive relations from infancy into childhood (Cohen, 1994).

\section{Graphing Conventions and Supplemental Estimates of Effect Size}

As detailed below, no longitudinal prediction analysis found a significant interaction between any infant predictor and the child's age in the repeated assessments of child conduct problems conducted over 4-13 years of age. That is, there was no evidence of significant differences in the slopes of conduct problems across increasing age associated with any predictor variable. Therefore, to simplify graphic presentations of the many findings, median numbers of conduct problems across all of the repeated assessments across 4-13 years are presented in all figures. Medians are presented instead of means because the distributions of conduct problems were skewed.

To supplement the interpretation of $\beta$ coefficients, estimates of effect sizes for the magnitude of predictive associations between the continuous temperament and parenting predictors and future conduct problems also were generated by comparing the level of conduct problem scores during 4-13 years of infants who were in the top 25\% of the unweighted sample distribution of each dimension of infant temperament and parenting to those of infants who were in the lower $25 \%$ of the distributions of these predictors. Because the distribution of conduct problem scores was skewed, the magnitudes of these differences between the two ends of the distributions were quantified using Rosnow and Rosenthal's (1996) effect-size correlation $\left(\rho_{\mathrm{ES}}\right)$ based on Spearman's rank correlations.

\section{RESULTS}

\section{Tests of Sample Bias}

Because a selected subset of the CNLSY offspring was used in the present analyses, tests were conducted to determine how the participants in the analyses differed from the remainder of the sample on key demographic variables. These cross-sectional comparisons were conducted using log-linear regression based on robust variance estimators in which the demographic variables were all entered simultaneously. A total of 2,027 offspring had both sufficient data on infant temperament and childhood conduct problems to be included in the factor analysis, compared to the 8,879 offspring who were not included in the factor analyses. There was a significantly greater proportion of male children (53.1\%) included in the analyses than excluded $(50.6 \%), \chi^{2}=4.20, d f=1, p<.05$. There was not a significant difference in the proportions of children of African American and Hispanic mothers. The families of children who were included had higher weighted total family incomes when the mother was age 30 years $(\$ 46,026$, expressed in 1986 dollars), than those of children who were excluded $(\$ 36,439), z=3.35, p<.001$. Similarly, children who were included had mothers with older ages at the birth of their first child (25.0 years), than children who were excluded (22.4 years), $z=3.35, p<.001$. Therefore, to more accurately estimate unbiased population parameters, all regression analyses controlled for the infant's sex, total adjusted family income when the 
mother was age 30, and the mother's age at first birth. Because of variations in income and maternal age across race-ethnic groups in the U.S., binary contrasts for maternal classifications of race-ethnicity as African American and Hispanic were also included as covariates in all cross-sectional and longitudinal analyses. In the CNLSY, the African American and Hispanic classifications were mutually exclusive.

\section{Demographic Differences in Temperament and Parenting During Infancy}

We conducted an initial series of analyses to describe any differences in infant temperament and parenting variables that are related to demographic factors. ${ }^{1}$ Cross-sectional regression models were estimated separately for each infant temperament and parenting scale (residualized on age in months of the infant at the time of the assessment), with child sex, raceethnicity, family income, and maternal age at first birth entered simultaneously as the predictor variables. Consistent with Gartstein and Rothbart (2003) and Martin et al. (1997), there was a small, but significant sex difference in fearfulness, with males rated as less fearful than female infants, $\beta=-.42, z=-2.63, p<.01$. Unlike these previous studies, there were not significant sex differences in infant fussiness or activity level. In addition, there were no significant differences in the levels of maternal responsiveness or cognitive stimulation, or in the prevalence of spanking, received by female and male infants.

Other demographic factors also were found to be associated with infant temperament. Mothers with higher incomes rated their infants as less fearful $(\beta=-.00, z=-4.81, p<.0001)$, but family income was not significantly related to the other dimensions of temperament. African American mothers rated their infants as fussier $(\beta=.89, z=7.16, p<.0001)$, more active $(\beta$ $=.97, z=4.90, p<.0001)$, more fearful $(\beta=1.12, z=5.46, p<.0001)$, and less predictable $(\beta=-.95, z=-6.62, p<.0001)$ than non-Hispanic European American mothers. Hispanic mothers rated their infants as more fearful $(\beta=.46, z=2.16, p<.04)$ and less predictable $(\beta=$ $-.66, z=-4.07, p<.0001)$ than non-Hispanic European American mothers. Women who first gave birth at older ages rated their infants as less fearful $(\beta=-.05, z=-2.66, p<.01)$.

Demographic differences in parenting during infancy-There were no significant differences in parenting related the to child's sex. African American mothers $(\beta=-.27, z=$ $-4.62, p<.0001)$ and Hispanic mothers $(\beta=-.33, z=-5.00, p<.0001)$ each reported providing lower levels of cognitive stimulation than did Non-Hispanic European American mothers. Interviewers rated African American mothers as providing lower levels of maternal responsiveness $(\beta=-.05, z=-2.92, p<.005)$ than non-Hispanic European American mothers; Hispanic mothers did not differ from Non-Hispanic European American mothers on this parenting variable.

In addition, African American mothers were more likely to spank their infants (13.0\%) than Non-Hispanic European American mothers (5.9\%). Hispanic mothers (7.8\%) did not spank their infants significantly more often than Non-Hispanic European American mothers. Women with higher family incomes reported providing greater cognitive stimulation of their infants $(\beta=.00, z=2.66, p<.01)$, were rated higher in maternal responsiveness $(\beta=.00, z=2.08, p$ $<.05)$, and were more likely to spank their infants $(\beta=.00, z=2.13, p<.05)$. Women who first gave birth at older ages received higher scores on cognitive stimulation $(\beta=.05, z=10.38$, $p<.0001)$ and maternal responsiveness $(\beta=.01, z=6.10, p<.0001)$, and were less likely to spank their infants $(\beta=-.08, z=-3.83, p<.0001)$.

\footnotetext{
${ }^{1}$ Complete tabled results of all cross-sectional and longitudinal analyses are available from the authors.
} 


\section{Results of Longitudinal Prediction Analyses}

Demographic Predictors of Child Conduct Problems-In a longitudinal model simultaneously testing the extent to which each demographic factor predicts repeated measures of child conduct problems across ages $4-13$ years, male sex of the infant $(\beta=.30, z=6.59, p$ $<.0001)$, family income $(\beta=-.00, z=-2.01, p<.05)$, African American race-ethnicity $(\beta=$. $13, z=2.69, p<.01)$, and maternal age at first birth $(\beta=-.03, z=-5.06, p<.0001)$ predicted mean levels of childhood conduct problems across $4-13$ years, but Hispanic race-ethnicity did not $(\beta=.01, z=0.12, p=.90)$ relative to non-Hispanic European American families. With the linear term for age across ages $4-13$ years in the model, the quadratic term for age also was significant $(\beta=.01, z=4.87, p<.0001)$, indicating a small but statistically significant decrease and then increase in mean conduct problems across this age span, as previously reported by Lahey et al. (2006) in an earlier analysis based on the CNLSY. Therefore, all of these demographic variables were included as covariates in all subsequent longitudinal analyses, including the contrast between Hispanic and non-Hispanic European American families, to reduce confounding of the infant predictors with demographic factors related to infant temperament, parenting during infancy, and childhood conduct problems.

Infant Temperament as a Predictor of Child Conduct Problems-In a longitudinal regression model with all demographic variables and each of the five temperament dimensions entered simultaneously as predictors, maternal ratings of conduct problems across $4-13$ years were predicted by maternal ratings of infant activity level $(\beta=.02, z=3.54, p<.0005)$, infant predictability $(\beta=-.02, z=-2.73, p<.01)$, infant fussiness $(\beta=.05, z=4.53, p<.0001)$, and the infant's positive affect $(\beta=-.02, z=-2.11, p<.04)$. When all interactions between each dimension of infant temperament and the child's age in each repeated assessment were added to the model, no interaction was significant. Furthermore, when all interactions with the quadratic term for age also were added to the model, none was significant. These findings are illustrated in Figure 1 using the graphing conventions described above.

Temperament-by-infant's sex interactions: When interactions between the infant's sex and each temperament dimension were added to the main effects model, the sex-by-fearfulness interaction was significant, $\beta=-.03, z=-2.26, p<.03$. This reflected a stronger positive predictive association between fearfulness and future conduct problems in girls. In addition, consistent with prediction of Shaw et al. (2000), the sex-by-fussiness interaction was significant, $\beta=.05, z=2.09, p<.04$, indicating a stronger positive predictive association between fussiness and future conduct problems in boys (Figure 2).

Temperament-by-race-ethnicity interactions: When all interactions between each temperament dimension and each race-ethnic group were tested, only the interaction between infant fussiness Hispanic ethnicity was significant, $\beta=-.06, z=-1.96, p<.05$. This indicated a stronger predictive relation between infant fussiness and future conduct problems in nonHispanic European American families than in Hispanic families.

Temperament-by-temperament interactions: When all two-way interactions among the five temperament dimensions were added to the main effects model, only the interaction between fussiness and predictability was significant, $\beta=.01, z=2.22, p<.03$. This appears to reflect a ceiling effect in which there was a stronger inverse relation between predictability and conduct problems among infants who are not already at risk due to high fussiness and viceversa. As shown in Figure 3, this means that infants with both low fussiness and high predictability are at very low risk for future conduct problems.

Supplemental effect size estimates for infant temperament: To facilitate interpretation, effect size estimates for the main effects of infant temperament were calculated by comparing 
levels of future conduct problems in infants in the top and bottom quartiles of the distributions of infant temperament scores. Effect-size correlations were $r_{\mathrm{ES}}=.21$ for infant fussiness and $r_{\mathrm{ES}}=-.20$ for predictability, which were in the "medium effect size" range of .15-.24 (Rosnow $\&$ Rosenthal, 1996). Effect-size correlations were $\rho_{\mathrm{ES}}=.12$ for infant activity level and $r_{\mathrm{ES}}=$ -.10 for positive affect which were in the "small effect size" range of $<.15$ (Rosnow \& Rosenthal, 1996). When the temperament-by-temperament interaction was considered, the effect size for predictability was $\rho_{\mathrm{ES}}=-.04$ ("small effect") among infants in the highest quartile of fussiness and $\rho_{\mathrm{ES}}=-.17$ ("medium effect") among infants in the lowest quartile of fussiness. When the temperament-by-sex interaction was considered, the effect size for fussiness was $\rho_{\mathrm{ES}}=.27$ ("large effect") for males and $\rho_{\mathrm{ES}}=.15$ ("medium effect") for girls. Similarly, the effect size for fearfulness was $\rho_{\mathrm{ES}}=.11$ ("small effect") for males and $\rho_{\mathrm{ES}}=$. 15 ("medium effect") for girls.

\section{Parenting During Infancy as a Predictor of Future Child Conduct Problems-}

With all demographic variables and each of the three dimensions of parenting during infancy entered simultaneously as predictors in the full sample, the hypothesis that childhood conduct problems across $4-13$ years would be predicted by cognitive stimulation was supported, $\beta=$ $-.13, z=-4.35, p<.0001$, but the hypothesis that childhood conduct problems would be predicted by maternal responsiveness was not supported, $\beta=-.15, z=-1.41, p=.16$. In addition, the predictive association between spanking during infancy and childhood conduct problems did reach the conventional .05 level of statistical significance, $\beta=.14, z=1.86, p=$. 06.

In order to at least partially control for potential child effects on parenting (Bell, 1977), the five dimensions of temperament were added to all subsequent longitudinal models assessing parenting. As illustrated in Figure 4, when all demographic variables, all dimensions of parenting, and all dimensions of infant temperament were controlled, childhood conduct problems were still robustly predicted by cognitive stimulation, $\beta=-.11, z=-3.76, p<.0005$, but not by spanking, $\beta=.10, z=1.34, p=.18$, or maternal responsiveness, $\beta=-.14, z=-1.34$, $p=.18$. When all interactions between each dimension of parenting during infancy and the child's linear and quadratic terms for age in each repeated assessment in these longitudinal analyses were added to the model, no interaction was significant.

Parenting-by-demographic interactions: When each 2-way interaction between the three parenting measures and the infant's sex were added to the main effects model, with temperament and other demographic variables controlled, none was significant. There also were no significant interactions between race-ethnicity and either cognitive stimulation or maternal responsiveness when temperament and other demographic variables were controlled. The hypothesis that spanking during infancy would predict childhood conduct problems more strongly among non-Hispanic European American families than African American families was not supported, as interaction did not reach the .05 level of significance $(\beta=-.24, z=-1.85$, $p=.06$ ). When African American and Hispanic families were compared on the strength of the predictive association between spanking and future conduct problems, the interaction term also did not reach the .05 level of significance $(\beta=-.31, z=-1.90, p=.06$ ). In contrast, there was a significant interaction between spanking and the comparison between Hispanic and nonHispanic European American ethnicity $(\beta=-.56, z=-3.24, p<.005)$. This indicated a positive predictive association between early spanking and later conduct problems in Non-Hispanic European American families, but not among Hispanic families (Figure 5).

Parenting-by-parenting interactions: When all 2-way interactions among the parenting dimensions were added to the main effects model, there were no significant interactions. 
Parenting-by-temperament interactions: We hypothesized significant interactions between maternal responsiveness and dimensions of infant temperament that the mother may find to be aversive (infant fussiness, fearfulness, and activity) in the prediction of future child conduct problems (Shaw et al., 2000). In analyses controlling all demographic variables, all temperament dimensions, and each parenting dimension, the hypothesized interaction of maternal responsiveness and temperament fearfulness was significant $(\beta=.06, z=2.03, p<$. $05)$. As illustrated in Figure 6, this interaction indicated that maternal responsiveness was a robust inverse predictor of childhood conduct problems only among infants low in fearfulness. The other hypothesized interactions between maternal responsiveness and fussiness and activity level were not statistically significant at $\mathrm{p}<.05$.

In addition, exploratory analyses revealed significant interactions between spanking and infant fussiness $(\beta=-.07, z=-2.23, p<.03)$ and spanking and infant positive affect $(\beta=-.05, z=$ $-2.14, p<.04)$. These interactions with spanking suggest ceiling effects, with the modest prediction of conduct problems from spanking being less strong among more fussy infants and among infants with more positive affect.

Supplemental effect size estimates for early parenting: A rank-order effect size correlation was calculated for the only significant main effect for early parenting by comparing levels of future conduct problems in infants in the top and bottom quartiles of cognitive stimulation scores. This estimate was in the "large effect" range for cognitive stimulation, $\rho_{\mathrm{ES}}=.26$ (Rosnow \& Rosenthal, 1996). When the interaction of race-ethnicity and spanking was considered, the effect-size correlation compared children who were spanked during infancy to those who were not in different groups. This was $\rho_{\mathrm{ES}}=.11$ ("small effect") among non-Hispanic European American families, $\rho_{\mathrm{ES}}=.05$ among African American families, and $\rho_{\mathrm{ES}}=-.01$ among Hispanic families.

When parenting-by-temperament interactions were considered, the effect size for predicting childhood conduct problems from greater maternal responsiveness during infancy was $\rho_{\mathrm{ES}}=$ -.25 ("large effect") among infants in the lowest quartile of the distribution of fearfulness scores and $\rho_{\mathrm{ES}}=-.09$ ("small effect") among infants in the highest quartile of fearfulness. The effect size for spanking during infancy was $\rho_{\mathrm{ES}}=.10$ ("small effect") among infants in the lowest quartile of the distribution of fussiness and $\rho_{\mathrm{ES}}=-.00$ among infants in the highest quartile of fussiness. The effect size for spanking during infancy was $\rho_{\mathrm{ES}}=.10$ ("small effect") among infants in the lowest quartile of the distribution of fussiness and $\rho_{\mathrm{ES}}=-.03$ among infants in the highest quartile of fussiness.

\section{DISCUSSION}

The results of the present longitudinal analyses support the idea that it is possible to predict conduct problems across childhood from temperament measured during the first year of life. In addition, dimensions of parenting during the first 12 months of life were found to predict future conduct problems when temperament was controlled. Because no interaction between the measures of temperament and parenting during infancy and the ages during childhood when conduct problems were measured (4-13 years) was significant, there was no evidence that the prediction of conduct problems was attenuated by length of the follow-up period.

To advance understanding of the role of infant temperament and parenting in the development of conduct problems, it is important to expose specific hypotheses to "severe risk of refutation" (Popper, 1963). Hypotheses that consistently are not supported are refuted and must be revised or replaced (Platt, 1964; Popper, 1963). In the present analyses, we tested a number of specific hypotheses based on theory and previous studies regarding infant temperament, early parenting, and their interactions. In addition, because much basic information remains to 
be learned in this area, systematic exploratory tests of main effects and interactions were conducted to induce additional hypotheses to be tested in future studies.

\section{Infant Temperament}

The present findings supported the specific hypothesis that maternal ratings of infant fussiness during the first year of life predict future maternal ratings of child conduct problems (Shaw et al., 2000; Teerikangas et al., 1998). In addition, these findings supported the more general hypothesis that two other temperament dimensions (infant activity level and predictability) that also may contribute to what has been referred to as "difficult temperament" (Guerin et al., 1997; Olson et al., 2000) independently predict future conduct problems. No hypothesis was offered regarding infant positive affect, but it also was found to independently predict future conduct problems inversely. The supplemental effect size estimates for the dimensions of infant temperament illustrated in Figure 1 reached the "medium effect" size range for infant fussiness and predictability, but were in the "small effect" size range for fearfulness and positive affect (Rosnow \& Rosenthal, 1996). The prediction of future conduct problems from infant temperament in the first year of life is generally consistent with the broad hypothesis that early individual differences in challenging temperament foster transactions with the environment that increase risk for early-onset conduct problems (Lahey \& Waldman, 2003; Moffitt, 1993; Shaw et al., 2000). In addition, the dimensions of fussiness and fearfulness refer to high levels of crying, irritability, and difficulty being soothed, which may reflect deficits in early emotion regulation (Kopp, 1989; Keenan, 2000; Keenan \& Shaw, 2003). Thus, these findings also are consistent with the hypothesis that deficits in early childhood emotion regulation foster later conduct problems (Keenan \& Shaw, 2003).

All interactions among the five temperament dimensions were tested without specific hypotheses, but the only significant interaction was between infant fussiness and predictability. This indicated that infants who were "easy" in the sense of being both low in fussiness and high in predictability were found to be at particularly low risk for childhood conduct problems.

There were few significant differences among race-ethnic groups in the extent to which infant temperament predicted future conduct problems. The one exception was that infant fussiness predicted child conduct problems better in Non-Hispanic European American families than among Hispanic families. If this finding is replicated, it will be important to explore its meaning in studies of the interface between child characteristics, culture, and other factors correlated with culture, such as income and neighborhood characteristics.

Consistent with the hypothesis of Keenan and Shaw (1997), we found few significant sex differences in mean levels of maternal ratings of temperament during the first year of life. Nonetheless, like Gartstein and Rothbart (2003) and Martin et al. (1997), we found that infant girls were rated slightly but significantly higher on fearfulness. In addition, we found two significant sex differences in the extent to which infant temperament predicted future childhood conduct problems that had not been reported previously. First, as hypothesized (Shaw et al., 2000), infant fussiness predicted future conduct problems more strongly in males than in females. Indeed, the effect size for the prediction of child conduct problems from infant fussiness in males ( $r_{\mathrm{ES}}=.27$; "large effect") was nearly twice as large as for girls $\left(r_{\mathrm{ES}}=.15\right.$; "medium effect").

It is not currently clear why fussiness would be a stronger predictor of future conduct problems in boys than girls. Some developmental models suggest that female and male infants are at similar risk for future conduct problems based on their infant characteristics, but sex differences in socialization beginning in toddlerhood reduce risks for female children more than for male children (Crick \& Zahn-Waxler, 2003; Keenan \& Shaw, 1997). Because there is evidence that girls may have a higher threshold for the same causal influences on antisocial behavior as boys 
(Van Hulle, Rodgers, D’Onofrio, Waldman, \& Lahey, 2007), understanding the reasons for such sex differences should be a priority for studies of the early origins of conduct problems.

The second interaction between a dimension of temperament and the infant's sex was not predicted. Infant fearfulness accounted for slightly but significantly more variance in the prediction of child conduct problems among female than male infants. Note that fearfulness was a positive predictor of future conduct problems in both sexes. This suggests that the disposition among infants to cry or turn away in response to some kinds of changes in the environment (e.g., presence of strangers, animals, or the caretaker leaving the room) does not index an inhibitory process in the same way that ratings of fearfulness do at age 3 years (e.g., Raine et al., 1998). Some support for this possibility can be seen in the almost complete lack of stability of maternal ratings of social fearfulness from 18 months to 4 years (Goldsmith, 1996). That is, it is possible that what is measured as "fearfulness" changes from infancy through the preschool period. Therefore, fearfulness during the first year of life may reflect irritability rather than an inhibitory process. The present finding that fearfulness and fussiness are positively correlated at $r=.34$ (Table 2 ) is consistent with this interpretation.

\section{Parenting During the First Year of Life}

Cognitive stimulation-The present findings supported the hypothesis based on Olson et al. (2000) that greater mother-reported cognitive stimulation of the infant protects infants from future conduct problems (Figure 4). Indeed, the supplemental effect size estimate was in the "large effect" range for cognitive stimulation (Rosnow \& Rosenthal, 1996). Why would cognitive stimulation during the first year of life robustly predict lower levels of future childhood conduct problems? One possibility is that the HOME-SF measure of cognitive stimulation broadly reflects affectionate and caring parenting (Pettit \& Bates, 1989) rather than only cognitive stimulation. A second possibility is that cognitive stimulation in infancy may facilitate language development, which is consistent with the hypothesis that individual differences in early language development play an important role in socialization (Keenan \& Shaw, 1997, 2003). That is, young children with better developed language may be better able to understand adult commands and express their needs to adults.

A third possibility is that language development may facilitate the development of emotion regulation (Kopp, 1989, 1992). Young children with better-developed language understand concepts of emotion better and display better emotion regulation than children with less advanced language skills (Eisenberg, Sadovsky, \& Spinrad, 2005; Kopp, 1992). In the context of the latter two hypotheses, it is important that Bradley, Corwyn, Burchinal, Pipes McAdoo, and García Coll (2001) found that HOME-SF cognitive stimulation was correlated with the development of receptive vocabulary in the CNLSY. This is consistent with the possibility that maternal cognitive stimulation operates partly by stimulating language development, which facilitates both the socialization of behavior and the development of emotion regulation. Fourth, because early parental cognitive stimulation is related to foster school readiness (Brooks-Gunn \& Markman, 2005) and because poor achievement in reading may increase risk for conduct problems (Trzesniewski, Moffitt, Caspi, Taylor, \& Maughan, 2006), it is possible that early cognitive stimulation indirectly influences risk through academic achievement.

Maternal responsiveness-In tests of main effects, we did not support the hypothesis that interviewer-rated maternal responsiveness during infancy inversely predicts childhood conduct problems (Kochanska, 1997a; Olson et al., 2000; Shaw et al., 2000; Wakschlag \& Hans, 1999). As discussed below, however, there was a significant interaction between maternal responsiveness and infant fearfulness. 
Spanking-The present findings did not confirm at the $p<.05$ level the prediction that spanking during infancy would predict future childhood conduct problems better among NonHispanic European American than African American families (Deater-Deckard \& Dodge, 1997). The unpredicted finding that spanking inversely predicts future conduct problems more strongly among Non-Hispanic European American infants than Hispanic infants had not been reported previously (Figure 5). It will be important to continue to investigate possible cultural differences in the effects of spanking during infancy, but the effect sizes for spanking appear to be small even among Non-Hispanic European American families.

\section{Parenting-by-Temperament Interactions}

The present findings did not support the hypothesis of an interaction between maternal responsiveness and infant fussiness Bates et al., 1998; Keenan, 2000; Sanson et al., 1993; Shaw et al., 2000). We did find, however, a significant interaction between early maternal responsiveness and another aspect of temperament. As illustrated in Figure 6, this indicated that maternal responsiveness was a robust predictor of future conduct problems among infants low in fearfulness (with an effect size in the "large" range), but was a weak predictor among fearful infants. It should be noted, however, that this interaction reflects the reverse on an earlier finding with older children. Kochanska (1997b) found that maternal responsiveness at age 23 years predicted less cheating in games by 4 -year-old children, but did so more strongly in children who were highly fearful at 2-3 years. Again, this suggests that the construct measured as fearfulness in infancy, which is positively related to conduct problems, may be quite different from fearfulness measured at 2-3 years. Unexpected interactions between spanking and fussiness and between spanking and positive affect also were significant, but the differences in effect sizes for spanking at different levels of these temperament were quite small.

\section{Prevention Trials}

The current findings are consistent with the hypothesis that interventions focusing on parenting during the first year of life would be beneficial in preventing future child conduct problems. Indeed, two controlled trials already have demonstrated that interventions designed to teach mothers of high-risk infants to be more responsive (and to engage in some parenting behaviors related to cognitive stimulation) yield both changes in parenting and concomitant improvements in the infant's cognitive development, emotional behavior, and cooperation through the preschool years (Landry, Smith, \& Swank, 2006; van den Boom, 1995). The results of these studies using randomized assignment to groups support the current finding that maternal parenting early in life predicts later conduct problems. When studies with different measurement strategies and different threats to their validity yield converging findings they increase confidence in those findings (Shadish, Cook, \& Campbell, 2002). Conversely, the present findings of long-term prediction of childhood conduct problems from infant parenting strongly support longer-term evaluations of these programs to determine if they reduce conduct problems during later childhood. The present findings also suggest that greater emphasis be placed on increasing maternal cognitive stimulation in such early intervention programs and suggests that interactions with infant temperament should be considered in their design and evaluation.

\section{Limitations}

The high cost of longitudinal studies of large and representative samples such as the CNLSY can be justified only when the studies serve multiple scientific and policy purposes. As a result, it is rarely possible to use lengthy questionnaires and the kinds of time-intensive observational measures of temperament and parenting that are feasible in smaller studies (e.g., Bates et al., 1998). Each type of study has its important advantages, however. Large studies of nationally representative samples have considerable statistical power (e.g., for detecting statistical 
interactions) and have high external validity because their results can be generalized to entire population (Shadish et al., 2002). In contrast, the results of smaller studies have less statistical power and their samples typically are not fully representative of any population of reference. Furthermore, small samples usually do allow comparisons of subgroups (e.g., sexes or raceethnic groups), which are often possible in larger studies. Nonetheless, the strong measurement possible in smaller samples affords them considerable internal validity. Smaller studies are ideal for conducting detailed examinations between constructs measured more briefly in larger studies. When the results of the two kinds of studies converge, their complementary advantages support strong conclusions (Shadish et al., 2002).

The measures of parenting used in the present analyses were largely based on maternal reports and concerns have been raised that maternal reports of parenting could be biased by recall requirements, social desirability, and parental mood (Morsbach \& Prinz, 2006). Although such biases may exist, maternal reports of parenting are substantially correlated with fathers' independent reports of the mother's parenting and by moderate to substantial correlations between maternal reports and observational measures of the same parenting behaviors (Lovejoy et al., 1999; Morsbach \& Prinz, 2006). These validating correlations are more impressive when one considers that observational measures of parenting are subject to biases themselves, including reactivity to the presence of observers, being limited to brief samples of parenting behavior, and a reduced ability to observe low-rate but important behaviors such as spanking. Nonetheless, the CNLSY did not include the kinds of independent observational assessments of mother-infant interactions that are free of maternal report biases (Keenan, 2000; Tronick, 1989). As a result, it is entirely possible that the predictive association between maternal reports of parenting and maternal ratings of later child conduct problems was affected by common method variance. Indeed, the major limitation of the present analyses is that both were based on maternal reports. It will be very important, therefore, to examine relations between infant temperament and reports of conduct problems from other informants in the future to rule out common method variance as an explanation.

Although the rate of spanking (i.e., 8.1\%) was low in the present sample, it is well within the expected range for this age group. Nonetheless, the low rate of spanking raises the possibility of floor effects. That is, a less strict and discrete measure of negative discipline might have yielded a stronger predictive effect because of less restriction of range in the predictor.

Nonetheless, there is evidence from a study of preschool children that "normative" levels of physical punishment at that age mostly reflect child effects on parental discipline rather than causal effects of physical punishment on child conduct problems (Jaffee, Caspi, Moffitt, PoloTomas, Price, \& Taylor, 2004). This raises the possibility that it may actually be desirable to use a strict definition of spanking during infancy. Precisely because it is uncommon, spanking an infant under 1 year of age may be extreme enough to function causally like harsher physical maltreatment does later in later childhood (Jaffee et al., 2004).

Because the items used to operationalize infant temperament and parenting were selected from broader pools of available items, it is possible that other sets of items might have provided even stronger predictions of future conduct problems. Mother-rated infant fussiness was the strongest predictor in both the present study and in Teerikangas et al. (1998). Nonetheless, because not all items from the IBQ (Rothbart, 1981) were used, it is possible that other unmeasured dimensions of temperament might be even more predictive than fussiness.

\section{Implications for Future Research}

Keeping the limitations of the present study in mind, it is striking that temperament and parenting during the first year of life predicted future conduct problems through age 13 years. Because the antisocial behavior with the greatest social impact does not occur until after puberty, however, it will be important to follow up the present analyses after sufficient data 
on adolescent outcomes in the CNLSY are released in late 2008. This also will have the advantage of allowing tests of predictions based on maternal reports of infant temperament and parenting using antisocial behavior assessed by youth self report as the outcome variable. In addition, these data will allow infant temperament and parenting to be linked to developmental trajectories of antisocial behavior across childhood and adolescence. Moffitt (1993) hypothesized that difficult infant temperament and early maladaptive parenting predicts only early-onset, stable antisocial behavior, but few data are yet available to test this hypothesis.

Perhaps the most important questions for future research is why early temperament and parenting predict child conduct problems. The CNLSY is a genetically informative sample that includes twins, full siblings, half siblings, and cousin pairs. This will allow us to use quasiexperimental analyses to test hypothesized causal links between infant factors and future conduct problems. It is clear that both temperament and conduct problems are moderately heritable (Goldsmith, Buss, \& Lemery, 1997; Rhee \& Waldman, 2002; Saudino, 2005). There also is evidence that maternal ratings of temperamental emotionality at 14-36 months predict maternal ratings of externalizing problems at age 4 years largely because of shared genetic influences (Schmitz, Fulker, Plomin, Zahn-Waxler, Emde, \& DeFries, 1999). Much remains to be learned about the mechanisms through which infant temperament, parenting during infancy, and later conduct problems are related, however.

\section{Acknowledgments}

This research was supported by grant R01 MH070025. The research was approved by the Institutional Review Board of each author's institution.

\section{References}

Achenbach TM. The Child Behavior Profile: I. Boys aged 6-11. Journal of Consulting and Clinical Psychology 1978;46:478-488. [PubMed: 670491]

Aguilar B, Sroufe LA, Egeland B, Carlson E. Distinguishing the early-onset/persistent and adolescenceonset antisocial behavior types: From birth to 16 years. Development and Psychopathology 2000;12:109-132. [PubMed: 10847620]

Anderson KE, Lytton H, Romney DM. Mothers' interaction with normal and conduct-disordered boys: Who affects whom? Developmental Psychology 1986;22:604-609.

Bates JE, Pettit GS, Dodge KA, Ridge B. Interaction of temperamental resistance to control and restrictive parenting in the development of externalizing behavior. Developmental Psychology 1998;34:982-995. [PubMed: 9779744]

Baydar N. Reliability and validity of temperament scales of the NLSY child assessments. Journal of Applied Developmental Psychology 1995;16:339-370.

Bell, RQ. Socialization findings re-examined. In: Bell, RQ.; Harper, RV., editors. Child effects on adults. Hillsdale, NJ: Erlbaum; 1977. p. 53-84.

Bornstein, MH. Parenting infants. In: Bornstein, MH., editor. Handbook of parenting: Vol. 1: Children and parenting. 2. Mahwah, NJ: Lawrence Erlbaum; 2002. p. 3-43.

Bornstein, MH.; Hahn, CS.; Suwalsky, JTD.; Haynes, OM. Socioeconomic status, parenting, and child development: The Hollingshead Four-Factor Index of Social Status and the Socioeconomic Index of Occupations. In: Bornstein, MH.; Bradley, RH., editors. Socioeconomic status, parenting, and child development. Mahwah, NJ: Lawrence Erlbaum; 2003. p. 29-82.

Bowlby J. The nature of the child's tie to his mother. International Journal of Psychoanalysis 1958;39:350-373. [PubMed: 13610508]

Bradley RH, Caldwell BM. The HOME Inventory and family demographics. Developmental Psychology 1984;20:315-320.

Bradley RH, Caldwell BM, Corwyn RF. The Child Care HOME Inventories: Assessing the quality of family child care homes. Early Childhood Research Quarterly 2003;18:294-309. 
Bradley RH, Corwyn RF, Pipes McAdoo H, García Coll C. The home environments of children in the United States Part I: Variations by age, ethnicity, and poverty status. Child Development 2001;72:1844-1867. [PubMed: 11768149]

Bradley RH, Corwyn RF, Burchinal M, Pipes McAdoo H, García Coll C. The home environments of children in the United States Part II: Relations with behavioral development through age thirteen. Child Development 2001;72:1868-1886. [PubMed: 11768150]

Brooks-Gunn J, Markman LB. The contribution of parenting to ethnic and racial gaps in school readiness. Future of Children 2005;15:139-168. [PubMed: 16130545]

Buss, AH.; Plomin, R. A temperament theory of personality development. New York: Wiley; 1975.

Caldwell, BM.; Bradley, RH. Home observation for measurement of the environment. Little Rock, AR: University of Arkansas at Little Rock; 1984.

Carey W. A simplified method of measuring infant temperament. Journal of Pediatrics 1970;77:188-194. [PubMed: 5431201]

Caspi A, McClay J, Moffitt TE, Mill J, Martin J, Craig IW, Taylor A, Poulton R. Role of genotype in the cycle of violence in maltreated children. Science 2002;297:851-854. [PubMed: 12161658]

Caspi A, Moffitt TE, Newman DL, Silva PA. Behavioral observations at age 3 predict adult psychiatric disorders: Longitudinal evidence from a birth cohort. Archives of General Psychiatry 1996;53:10331039. [PubMed: 8911226]

Chess, S.; Thomas, A. Origins and evolution of behavior disorders: From infancy to early adult life. Cambridge, MA: Harvard University Press; 1984.

Cohen, J. Statistical power analysis for the behavioral sciences. 2. Hillsdale, NJ: Lawrence Erlbaum; 1988.

Cohen J. The earth is round ( $\mathrm{p}$ <.05). American Psychologist 1994;49:997-1003.

Cohen P. To be or not to be: Control and balancing of Type I and Type II errors. Evaluation and Program Planning 1982;5:247-253.

Colder CR, Mott JA, Berman AS. The interactive effects of infant activity level and fear on growth trajectories of early childhood behavior problems. Development and Psychopathology 2002;14:124. [PubMed: 11893087]

Crick NR, Zahn-Waxler C. The development of psychopathology in females and males: Current progress and future challenges. Development and Psychopathology 2003;15:719-742. [PubMed: 14582938]

Deater-Deckard K, Dodge KA. Externalizing behavior problems and discipline revisited: nonlinear effects and variation by culture, context, and gender. Psychological Inquiry 1997;8:161-175.

D'Onofrio BM, Van Hulle CA, Waldman ID, Rodgers JL, Harden KP, Rathouz PJ, Lahey BB. Smoking during pregnancy and offspring externalizing problems: An exploration of genetic and environmental confounds. Development and Psychopathology 2008;20:139-164. [PubMed: 18211732]

Dunn, W. The Infant/Toddler Sensory Profile Manual. San Antonio, TX: The Psychological Corporation; 2002.

Eisenberg N, Sadovsky A, Spinrad TL. Associations of emotion-related regulation with language skills, emotion knowledge, and academic outcomes. New Directions in Child and Adolescent Development 2005;109:109-118.

Gartstein MA, Rothbart MK. Studying infant temperament via the revised infant behavior questionnaire. Infant Behavior and Development 2003;26:64-86.

Goldsmith HH. Studying temperament via construction of the Toddler Behavior Assessment Questionnaire. Child Development 1996;67:218-235. [PubMed: 8605830]

Goldsmith HH, Buss KA, Lemery KS. Toddler and childhood temperament; expanded content, stronger genetic evidence, new evidence for the importance of environment. Developmental Psychology 1997;33:891-905. [PubMed: 9383612]

Goldsmith HH, Van Hulle CA, Arneson CL, Schreiber JE, Gernsbacher MA. A population based twin study of parentally reported tactile and auditory defensiveness in young children. Journal of Abnormal Child Psychology 2006;34:393-407. [PubMed: 16649001]

Guerin DW, Gottfried AW, Thomas CW. Difficult temperament and behaviour problems: A longitudinal study from 1.5 to 12 years. International Journal of Behavioral Development 1997;21:71-90. 
Jaffee SR, Caspi A, Moffitt TE, Polo-Tomas M, Price TS, Taylor A. The limits of child effects: Evidence for genetically mediated child effects on corporal punishment but not on physical maltreatment. Developmental Psychology 2004;40:1047-1058. [PubMed: 15535755]

Karrass J, VanDeventer MC, Braungart-Rieker JM. Predicting shared parent-child book reading in infancy. Journal of Family Psychology 2003;17:134-146. [PubMed: 12666469]

Keenan K. Emotion dysregulation as a risk factor for child psychopathology. Clinical Psychology: Science and Practice 2000;7:418-434.

Keenan K, Shaw D. Developmental and social influences on young girls' early problem behavior. Psychological Bulletin 1997;121:95-113. [PubMed: 9000893]

Keenan, K.; Shaw, DS. Starting at the beginning: Exploring the etiology of antisocial behavior in the first years of life. In: Lahey, BB.; Moffitt, TE.; Caspi, A., editors. Causes of conduct disorder and juvenile delinquency. New York: Guilford Press; 2003. p. 153-181.

Kochanska G. Mutually responsive orientation between mothers and their young children: Implications for early socialization. Child Development 1997a;68:94-112. [PubMed: 9084128]

Kochanska G. Multiple pathways to conscience for children with different temperaments: From toddlerhood to age 5. Developmental Psychology 1997b;33:228-240. [PubMed: 9147832]

Kopp CB. Regulation of distress and negative emotions: A developmental view. Developmental Psychology 1989;25:343-354.

Kopp, C. Emotional distress and control in young children. In: Eisenberg, N.; Fabes, RA., editors. Emotion and its regulation in early development: New Directions in Child Development. Vol. 55. San Francisco: Jossey-Bass; 1992. p. 41-56.

Lahey, BB.; Miller, TL.; Gordon, RA.; Riley, A. Developmental epidemiology of the disruptive behavior disorders. In: Quay, H.; Hogan, A., editors. Handbook of the disruptive behavior disorders. New York: Plenum; 1999. p. 23-48.

Lahey BB, Van Hulle CA, Waldman ID, Rodgers JL, D’Onofrio BM, Pedlow S, Rathouz PJ, Keenan K. Testing descriptive hypotheses regarding sex differences in the development of conduct problems and delinquency. Journal of Abnormal Child Psychology 2006;34:737-755. [PubMed: 17033935]

Landry SH, Smith KE, Swank PR. Responsive parenting: Establishing early foundations for social, communication, and independent problem-solving skills. Developmental Psychology 2006;42:627642. [PubMed: 16802896]

Lerner, JV.; Nitz, K.; Talwar, R.; Lerner, RM. On the functional significance of temperamental individuality: A developmental contextual view of the concept of goodness of fit. In: Kohnstamm, GA.; Bates, JE.; Rothbart, MK., editors. Temperament in childhood. West Sussex: Wiley; 1989. p. 509-522.

Linver MR, Brooks-Gunn J, Kohen DE. Family processes as pathways from income to young children's development. Developmental Psychology 2002;38:719-734. [PubMed: 12220050]

Little, RJA.; Rubin, DB. Statistical analysis with missing data. New York: Wiley; 1987.

Loeber, R.; Farrington, DP.; Stouthamer-Loeber, M.; Van Kammen, W. Antisocial behavior and mental health problems: Explanatory factors in childhood and adolescence. Mahwah, NJ: Lawrence Erlbaum; 1998.

Lovejoy MC, Weis R, O'Hare E, Rubin EC. Development and initial validation of the Parent Behavior Inventory. Psychological Assessment 1999;11:534-545.

Lytton H. Child and parent effects in boys' conduct disorder: A reinterpretation. Developmental Psychology 1990;26:683-697.

Maccoby EE. The role of parents in the socialization of children: An historical overview. Developmental Psychology 1992;28:1006-1017.

Martin R, Wisenbaker J, Baker J, Huttunen M. Gender differences in temperament at six months and five years. Infant Behavior and Development 1997;20:339-347.

McLoyd VC, Smith J. Physical discipline and behavior problems in African American, European American, and Hispanic children: Emotional support as a moderator. Journal of Marriage and Family 2002;64:40-53.

Meaney MJ, Szyf M. Maternal care as a model for experience-dependent chromatin plasticity? Trends in Neuroscience 2005;28:456-463. 
Moffitt TE. Adolescence-limited and life-course-persistent antisocial behavior: A developmental taxonomy. Psychological Review 1993;100:674-701. [PubMed: 8255953]

Moffitt, TE. Life-course persistent versus adolescence-limited antisocial behavior. In: Cicchetti, D.; Cohen, D., editors. Developmental Psychopathology. 2. New York: Wiley; 2006.

Moffitt, TE.; Caspi, A.; Rutter, M.; Silva, P. Sex differences in antisocial behaviour. Cambridge, UK: Cambridge University Press; 2001.

Morrell J, Murray L. Parenting and the development of conduct disorder and hyperactive symptoms in childhood: A prospective longitudinal study from 2 months to 8 years. Journal of Child Psychology and Psychiatry 2003;44:489-508. [PubMed: 12751842]

Morsbach SK, Prinz RJ. Understanding and improving the validity of self-report of parenting. Clinical Child and Family Psychology Review 2006;9:1-21. [PubMed: 16636897]

Mott, FL.; Baker, PC.; Ball, DE.; Keck, CK.; Lenhart, SM. The NLSY children 1992:Description and evaluation. Columbus, OH: Ohio State University Center for Human Resource Research; 1995.

Olson SL, Bates JE, Sandy JM, Lanthier R. Early developmental precursors of externalizing behavior in middle childhood and adolescence. Journal of Abnormal Child Psychology 2000;28:119-133. [PubMed: 10834765]

Patterson, GR. Coercive Family Processes. Eugene, OR: Castalia; 1982.

Peterson JL, Zill N. Marital disruption, parent-child relationships, and behavior problems in children. Journal of Marriage and the Family 1986;48:295-307.

Pettit GS, Bates JE. Family interaction patterns and children's behavior problems from infancy to 4 years. Developmental Psychology 1989;25:413-420.

Platt JR. Strong inference. Science 1964;146:347-353. [PubMed: 17739513]

Popper, K. Conjectures and refutations. London: Routledge and Kegan Paul; 1963.

Prior M, Smart D, Sanson A, Oberklaid F. Longitudinal predictors of behavioural adjustment in preadolescent children. Australian and New Zealand Journal of Psychiatry 2001;35:297-307. [PubMed: 11437802]

Raine A, Reynolds C, Venables PH, Mednick SA, Farrington DP. Fearlessness, stimulation-seeking, and large body size at age 3 years as early predispositions to childhood aggression at age 11 years. Archives of General Psychiatry 1998;55:745-751. [PubMed: 9707386]

Rhee SH, Waldman ID. Genetic and environmental influences on antisocial behavior: A meta-analysis of twin and adoption studies. Psychological Bulletin 2002;128:490-529. [PubMed: 12002699]

Rosnow RL, Rosenthal R. Computing contrasts, effect sizes, and counternulls on other people's published data: General procedures for research consumers. Pyschological Methods 1996;1:331-340.

Rothbart MK. Measurement of temperament in infancy. Child Development 1981;2:569-578.

Rothbart, MK.; Bates, JE. Temperament. In: Eisenberg, N., editor. Handbook of child psychology, Volume 3: Social, emotional, and personality development. 5. New York: John Wiley; 1998. p. 105-176.

Sanson A, Hemphill SA, Smart D. Connections between temperament and social development: A review. Social Development 2004;13:142-170.

Sanson A, Prior M, Smart D, Oberklaid F. Gender differences in aggression in childhood: Implications for a peaceful world. Australian Psychologist 1993;28:86-92.

Saudino KS. Behavioral genetics and child temperament. Developmental and Behavioral pediatrics 2005;26:214-223.

Schmitz SS, Fulker DW, Plomin R, Zahn-Waxler C, Emde R, DeFries JC. Temperament and problem behavior during early childhood. International Journal of Behavioral Development 1999;23:333355.

Shadish, W.; Cook, T.; Campbell, D. Experimental and Quasi-Experimental Designs for Generalized Causal Inference. Boston: Houghton Mifflin; 2002.

Shaw DS, Bell RQ, Gilliom M. A truly early starter model of antisocial behavior revisited. Clinical Child and Family Psychology Review 2000;3:155-172. [PubMed: 11225751]

Shaw DS, Winslow EB, Owens EB, Vondra JI, Cohn JF, Bell RQ. The development of early externalizing problems among children from low-income families: A transformational perspective. Journal of Abnormal Child Psychology 1998;26:95-107. [PubMed: 9634132] 
Slade EP, Wissow LS. Spanking in early childhood and later behavior problems: A prospective study of infants and young toddlers. Pediatrics 2004;113:1321-1330. [PubMed: 15121948]

Teerikangas OM, Aronen ET, Martin RP, Huttunen MO. Effects of infant temperament and early intervention on the psychiatric symptoms of adolescents. Journal of the American Academy of Child and Adolescent Psychiatry 1998;37:1070-1076. [PubMed: 9785718]

Thomas, A.; Chess, S. Temperament and development. New York: Brunner/Mazel; 1977.

Trzesniewski KH, Moffitt TE, Caspi A, Taylor A, Maughan B. Revisiting the association between reading achievement and antisocial behavior: New evidence of an environmental explanation from a twin study. Child Development 2006;77:72-88. [PubMed: 16460526]

Tronick EZ. Emotions and emotional communication in infants. American Psychologist 1989;44:112119. [PubMed: 2653124]

Van Hulle CA, Rodgers JL, D'Onofrio BM, Waldman ID, Lahey BB. Sex differences in the causes of self-reported adolescent delinquency. Journal of Abnormal Psychology 2007;116:236-248. [PubMed: 17516757]

van den Boom DC. Do first-year intervention effects endure? Follow-up during toddlerhood of a sample of Dutch irritable infants. Child Development 1995;66:1798-1816. [PubMed: 8556900]

Wakschlag LS, Hans SL. Relation of maternal responsiveness during infancy to the development of behavior problems in high-risk youths. Developmental Psychology 1999;35:569-579. [PubMed: 10082027]

Weiss B, Dodge KA, Bates GE, Pettit GS. Some consequences of early harsh discipline: Child aggression and a maladaptive social information processing style. Child Development 1992;63:1321-1335. [PubMed: 1446555] 

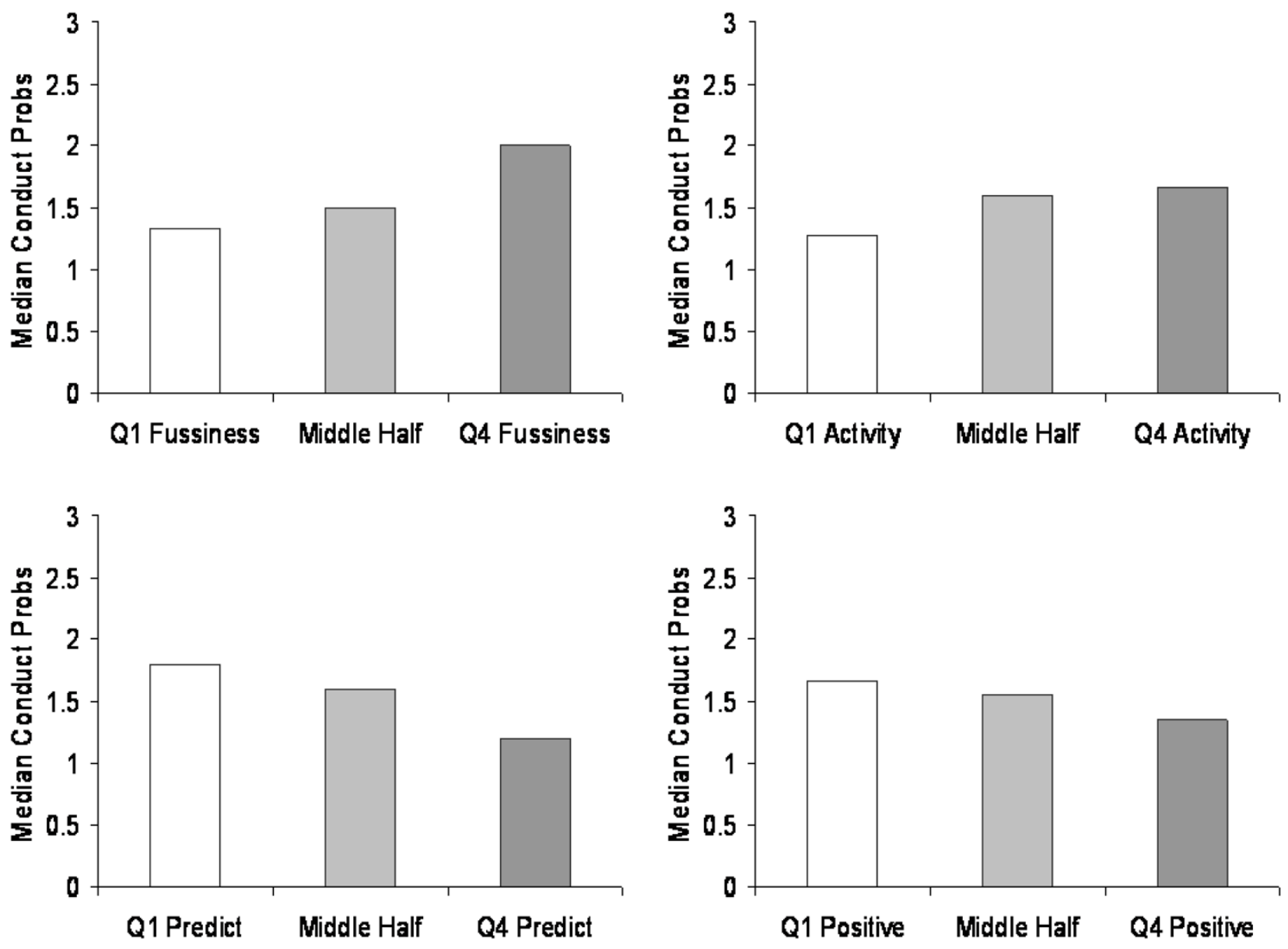

Figure 1.

Weighted medians of the average maternal rating of child conduct problems across 4-13 years of age among children with maternal ratings in the top $25 \%$, middle $50 \%$, or bottom $25 \%$ of the sample distributions of fussiness (upper left), activity level (upper right), predictability of rhythms and mood (lower left), and positive affect (lower right) during infancy. Note that prospective associations of these infant predictors with later conduct problems were testing using repeated measures of conduct problems across 4-13 years in longitudinal analyses; the median level of conduct problems across these ages is used here only to facilitate graphic presentation. 

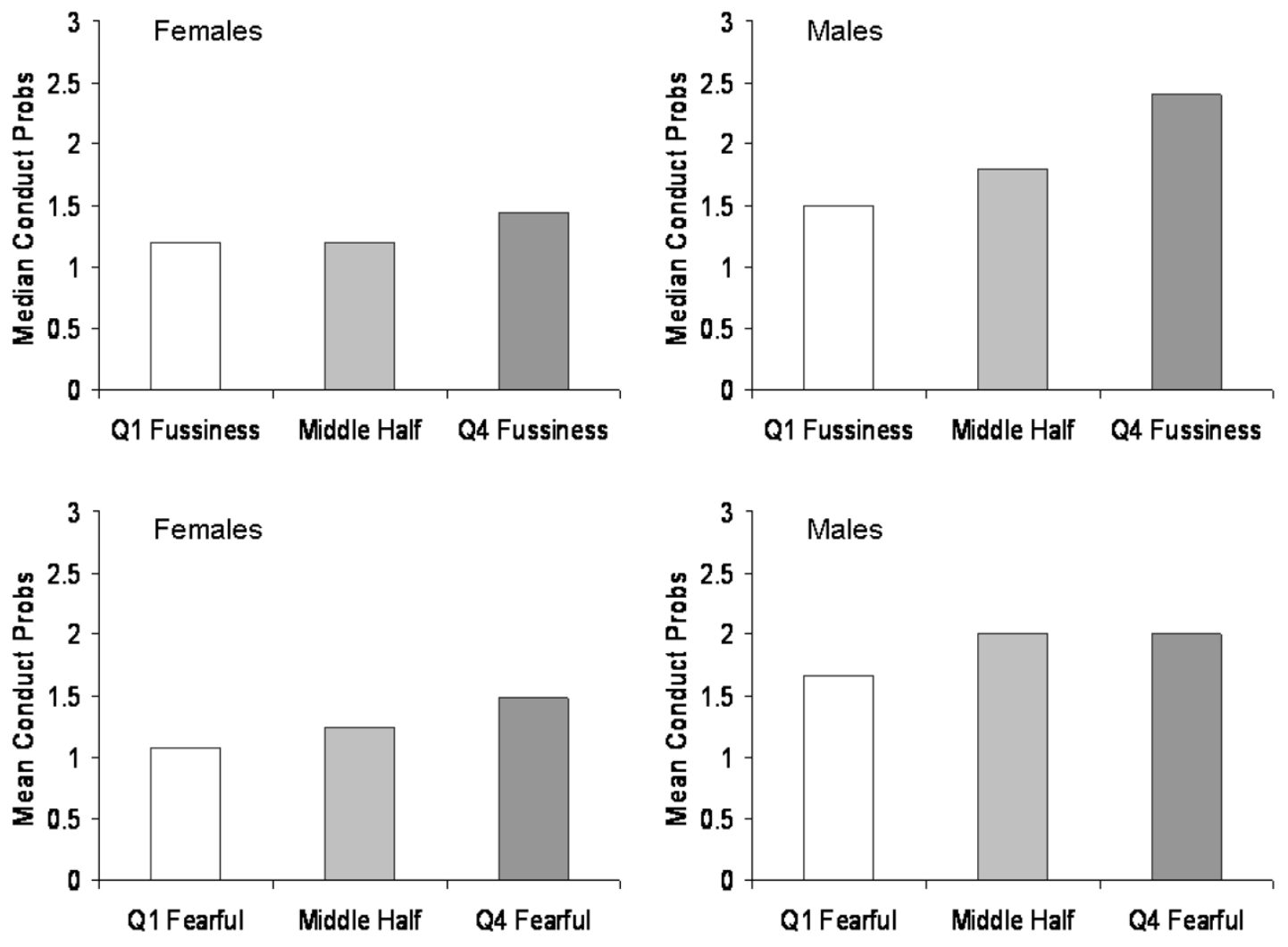

Figure 2.

Weighted medians of the average maternal rating of child conduct problems across 4-13 years of age among infants with maternal ratings in the top $25 \%$, middle $50 \%$, or bottom $25 \%$ of the sample distributions of the two dimensions of infant temperament, presented separately for girls and boys for predictors for which there were significant interactions with the infant's sex: fussiness (upper left and right) and fearfulness (lower left and right). Note that prospective associations of these infant predictors with later conduct problems were testing using repeated measures of conduct problems across 4-13 years in longitudinal analyses; the median level of conduct problems across these ages is used here only to facilitate graphic presentation. 


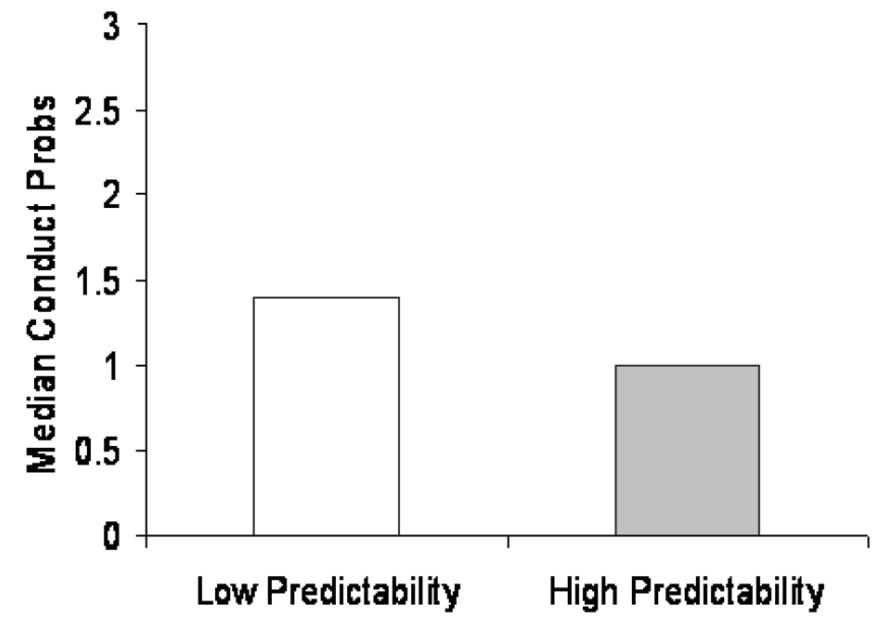

Lowest Quartile of Fussiness

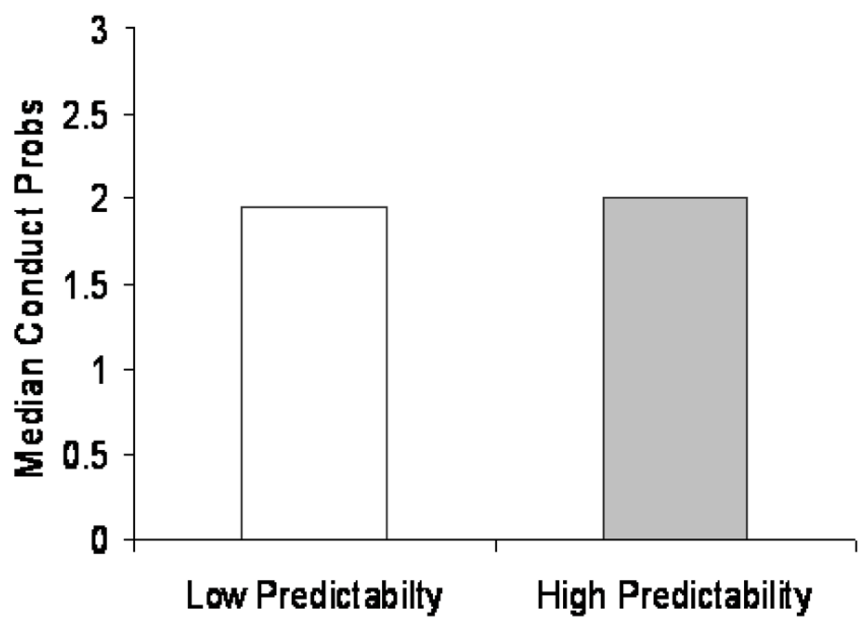

Highest Quartile of Fussiness

Figure 3.

Weighted medians of the average maternal rating of child conduct problems across 4-13 years of age among infants with maternal ratings in the top or bottom quartile of the sample distributions of infant predictability, presented separately for infants with maternal ratings in the top quartile (left panel) or bottom quartile (right panel) of the sample distributions of infant fussiness to illustrated the significant fussiness-by-predictability interaction. Note that prospective associations of these infant predictors with later conduct problems were testing using repeated measures of conduct problems across 4-13 years in longitudinal analyses; the median level of conduct problems across these ages is used here only to facilitate graphic presentation. 


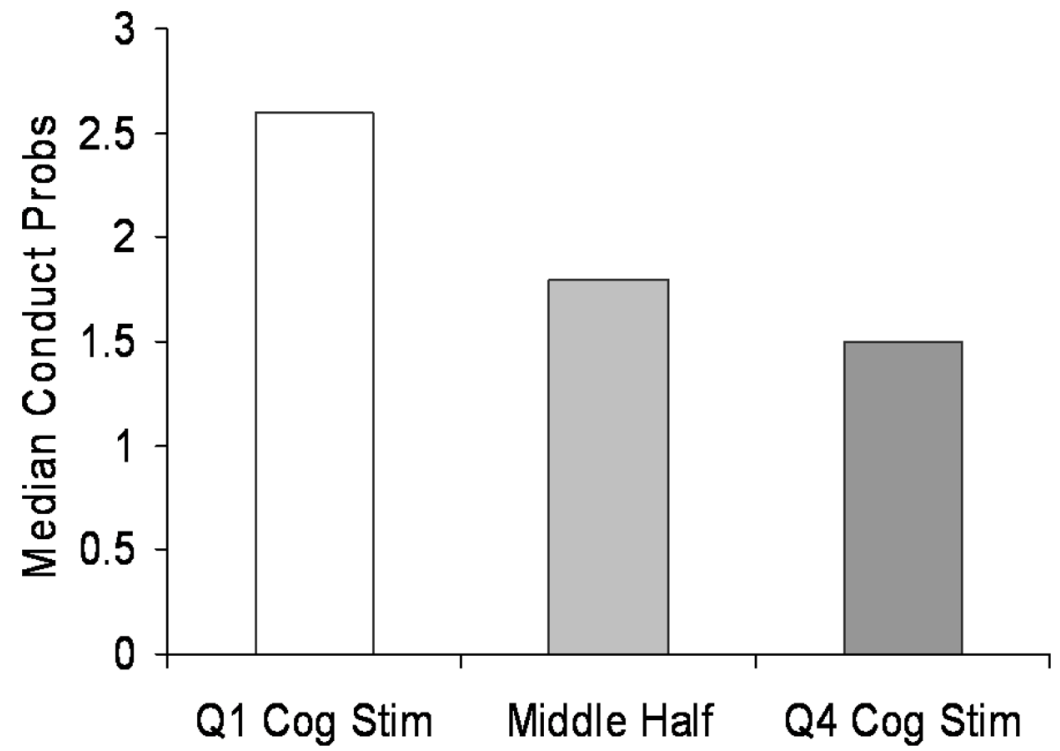

Figure 4.

Weighted medians of the average maternal rating of child conduct problems across 4-13 years of age among children with maternal reports in the top $25 \%$, middle $50 \%$, or bottom $25 \%$ of the sample distribution of cognitive stimulation of the infant. Note that the prospective association of cognitive stimulation during infancy with later conduct problems was tested using repeated measures of conduct problems across 4-13 years in longitudinal analyses; the median level of conduct problems across these ages is used here only to facilitate graphic presentation. 


\section{$\square$ Not Spanked $\square$ Spanked}

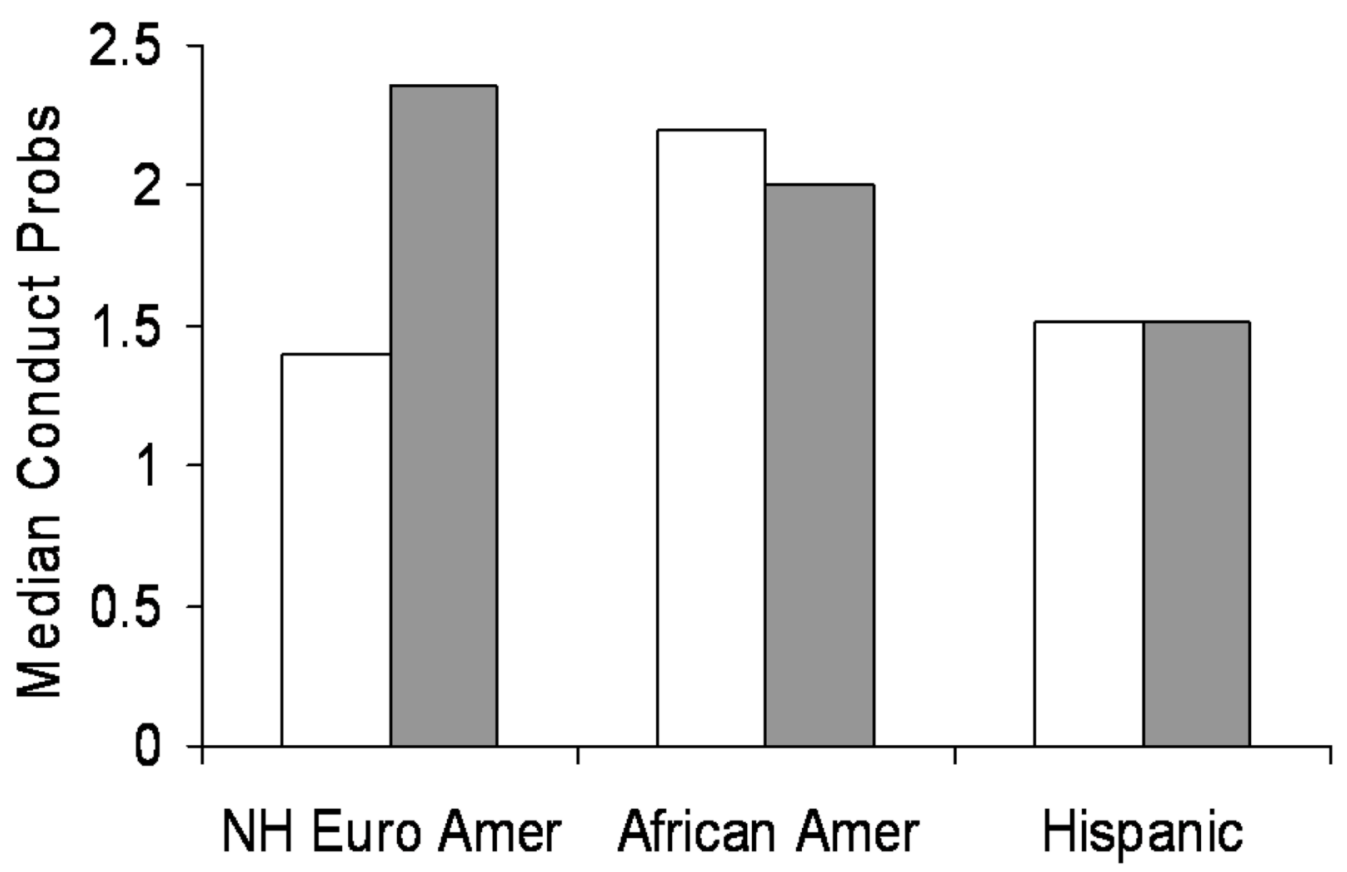

Figure 5.

Weighted medians of the average maternal rating of child conduct problems across 4-13 years of age among children with who were or were not spanked during the first year of life, separately for Non-Hispanic European American, African American, and Hispanic infants. Note that the prospective associations of these infant predictors with later conduct problems were tested using repeated measures of conduct problems across 4-13 years in longitudinal analyses; the median level of conduct problems across these ages is used here only to facilitate graphic presentation. 


\section{$\square$ Low Responsiveness $\square$ High Responsiveness}

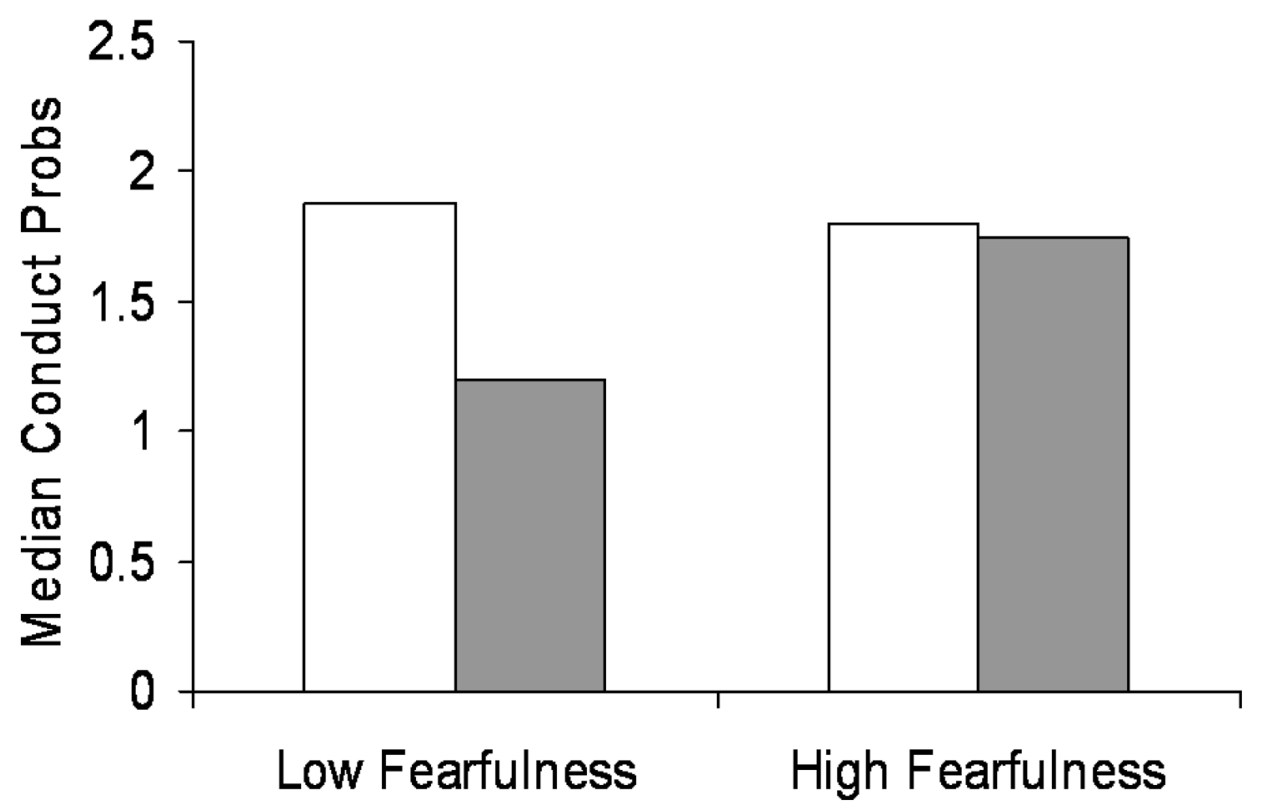

Figure 6.

Weighted medians of the average maternal rating of child conduct problems across 4-13 years of age among children whose mothers were rated by interviewers as being in the top or bottom quartiles of maternal responsiveness during the first year of life, presented separately for infants in the lowest quartile (left panel) or in the highest quartile of the distribution of infant fearfulness scores (right panel). Note that the prospective associations of these infant predictors with later conduct problems were tested using repeated measures of conduct problems across 4-13 years in longitudinal analyses; the median level of conduct problems across these ages is used here only to facilitate graphic presentation. 


\section{Table 1}

Unweighted proportions, means, and standard deviations (in parentheses) for demographic variables, infant temperament, parenting during infancy, and child conduct problems in female and male participants.

\begin{tabular}{|c|c|c|}
\hline & $\begin{array}{c}\underline{\text { Girls }} \\
\mathrm{N}=\mathbf{8 7 8}(\mathbf{4 7 . 4 \% )})\end{array}$ & $\begin{array}{c}\underline{\text { Boys }} \\
\mathrm{N}=976(52.6 \%)\end{array}$ \\
\hline \multicolumn{3}{|l|}{ Infant's Race-Ethnic Classification: } \\
\hline Hispanic & $166(18.9 \%)$ & $184(18.8 \%)$ \\
\hline African American & $242(27.6 \%)$ & $260(26.6 \%)$ \\
\hline Non-Hispanic European American* & $470(53.5 \%)$ & $532(54.5 \%)$ \\
\hline Total Family Income at Age (1986 U.S. Dollars) & $\$ 43,543(106,928)$ & $\$ 33,653(59,251)$ \\
\hline Mother's Age at First Birth & $24.1(5.0)$ & $23.8(5.2)$ \\
\hline Mean Age in Months at Time of Assessment of Temperament and Parenting in First Year of Life & $5.7(3.5)$ & $5.8(3.4)$ \\
\hline \multirow[t]{5}{*}{ Numbers of Assessments of Conduct Problems at Each Age in Years } & 4 or $5: 848$ & 4 or $5: 940$ \\
\hline & 6 or $7: 827$ & 6 or 7: 919 \\
\hline & 8 or $9: 746$ & 8 or 9: 809 \\
\hline & 10 or 11: 626 & 10 or $11: 701$ \\
\hline & 12 or $13: 544$ & 12 or $13: 597$ \\
\hline \multicolumn{3}{|l|}{ Maternal Ratings of Infant Temperament (z-scores) ${ }^{1}$ : } \\
\hline Activity & $-0.25(3.27)$ & $0.16(3.22)$ \\
\hline \multirow[t]{2}{*}{ Fearfulness } & $0.18(3.27)$ & $-0.21(3.18)$ \\
\hline & $-0.06(2.02)$ & $0.04(1.99)$ \\
\hline Fussiness & $-0.02(2.61)$ & $-0.02(2.52)$ \\
\hline Positive Affect & $0.06(2.37)$ & $-0.05(2.39)$ \\
\hline \multicolumn{3}{|l|}{ Predictability } \\
\hline \multicolumn{3}{|l|}{ HOME-SF Parenting Measures (z-scores) ${ }^{l}:$} \\
\hline Maternal Responsiveness & $0.00(0.24)$ & $0.00(0.24)$ \\
\hline Cognitive Stimulation & $-0.00(0.92)$ & $-0.02(0.87)$ \\
\hline Spanking Infant & $65(7.4 \%)$ & $85(8.8 \%)$ \\
\hline Mean Conduct Problems Over 4-13 years (z-scores) & $-0.20(0.85)$ & $0.16(1.07)$ \\
\hline
\end{tabular}

${ }^{l}$ Residualized on the infant's age in months at the time of assessment for this table. Standardized $\mathrm{z}$ scores for temperament, parenting, and conduct problems are presented here to facilitate comparisons of girls and boys, but raw scores were used in statistical analyses. 


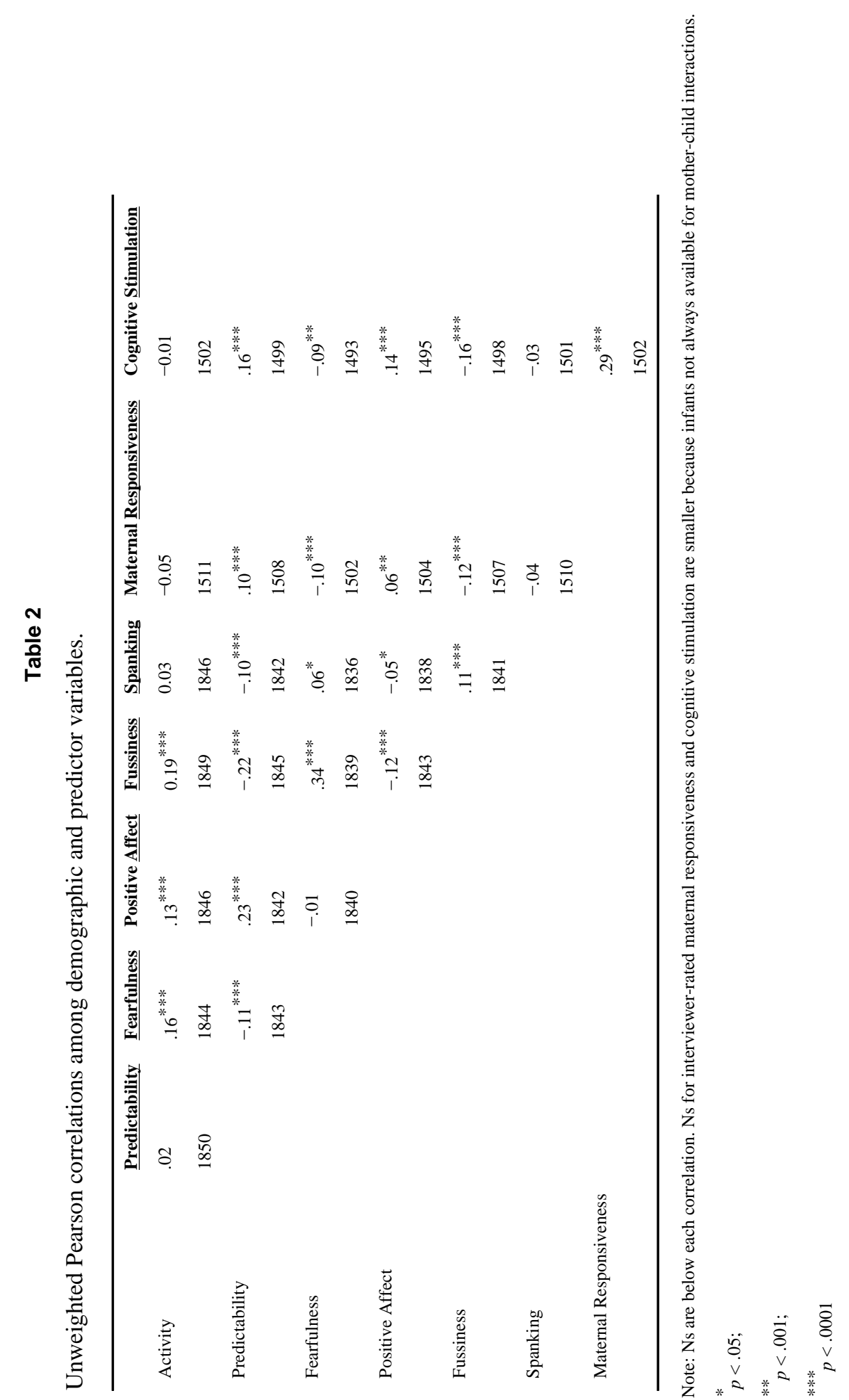

